\title{
Effect of Ethanol Fuel Additive on Diesel Emissions
}

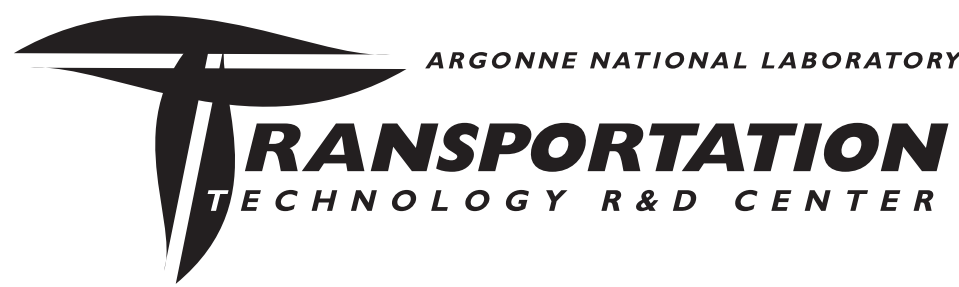

Center for Transportation Research Argonne National Laboratory

Operated by The University of Chicago, under Contract W-31-109-Eng-38, for the

United States Department of Energy 


\section{Argonne National Laboratory}

Argonne National Laboratory, with facilities in the states of Illinois and Idaho, is owned by the United States Government and operated by The University of Chicago under the provisions of a contract with the Department of Energy.

This technical memorandum is a product of Argonne's Energy Systems Division.

For information on the division's scientific and engineering activities, contact:

Director, Energy Systems Division

Argonne National Laboratory

Argonne, Illinois 60439-4815

Telephone (630) 252-3724

Presented in this technical memorandum are preliminary results of ongoing work or work that is more limited in scope and depth than that described in formal reports issued by the ES Division.

Publishing support services were provided by Argonne's Information and Publishing Division (for more information, see IPD's home page: http://www.ipd.anl.gov/).

\section{Disclaimer}

This report was prepared as an account of work sponsored by an agency of the United States Government. Neither the United States Government nor any agency thereof, nor The University of Chicago, nor any of their employees or officers, makes any warranty, express or implied, or assumes any legal liability or responsibility for the accuracy, completeness, or usefulness of any information, apparatus, product, or process disclosed, or represents that its use would not infringe privately owned rights. Reference herein to any specific commercial product, process, or service by trade name, trademark, manufacturer, or otherwise does not necessarily constitute or imply its endorsement, recommendation, or favoring by the United States Government or any agency thereof. The views and opinions of document authors expressed herein do not necessarily state or reflect those of the United States Government or any agency thereof, Argonne National Laboratory, or The University of Chicago.

Available electronically at http://www.doe.gov/bridge Available for a processing fee to U.S. Department of Energy and its contractors, in paper, from:

U.S. Department of Energy

Office of Scientific and Technical Information

P.O. Box 62

Oak Ridge, TN 37831-0062

phone: (865) 576-8401

fax: (865) 576-5728

email: reports@adonis.osti.gov 


\section{Effect of Ethanol Fuel Additive on Diesel Emissions}

by R.L. Cole, R.B. Poola, R. Sekar, J.E. Schaus, ${ }^{*}$ and P. McPartlin*

Center for Transportation Research, Energy Systems Division,

Argonne National Laboratory, 9700 South Cass Avenue, Argonne, Illinois 60439

August 2000

Work sponsored by State of Illinois, Department of Commerce and Community Affairs, and U.S. Department of Energy, Office of Advanced Automotive Technology

* Schaus and McPartlin are affiliated with AutoResearch Laboratories, Inc., Chicago, Illinois. 
This report is printed on recycled paper. 


\section{Contents}

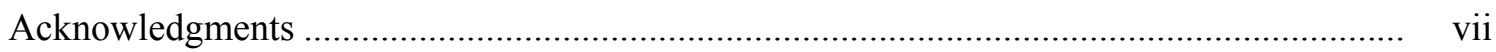

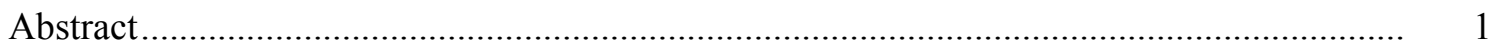

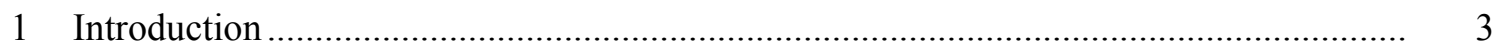

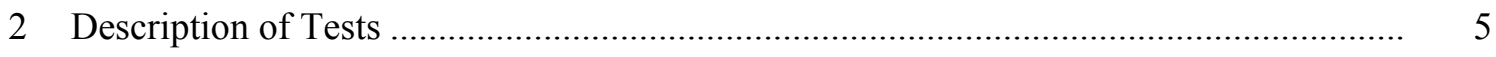

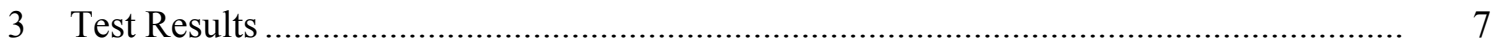

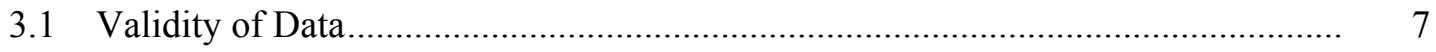

3.2 Particulate Emissions on the Test Matrix.............................................................. 7

3.3 Nitrogen Oxides Emissions on the Test Matrix .............................................. 12

3.4 Hydrocarbon Emissions on the Test Matrix...................................................... 17

3.5 Carbon Monoxide Emissions on the Test Matrix ….............................................. 23

3.6 Emissions at Idle ............................................................................................. 25

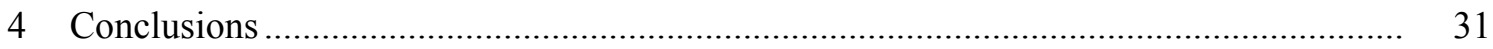

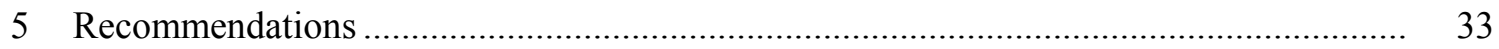

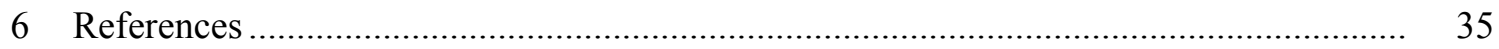

\section{Appendix}

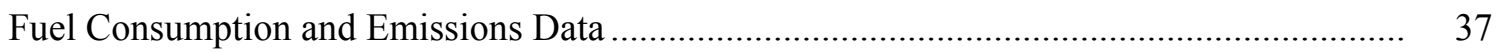

\section{Figures}

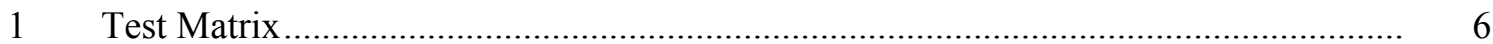

2 Effect of Ethanol Content of Fuel on BSPM Emissions at 3,000 rpm,

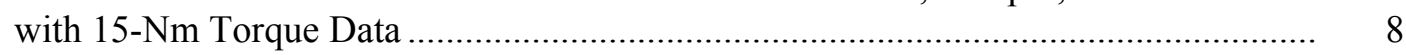

3 Effect of Ethanol Content of Fuel on BSPM Emissions at 3,000 rpm, without 15-Nm Torque Data .............................................................................. 8

4 Effect of Ethanol Content of Fuel on BSPM Emissions at 2,500 rpm........................ 9

$5 \quad$ Effect of Ethanol Content of Fuel on BSPM Emissions at 2,000 rpm......................... 9 
A

\section{Figures (Cont.)}

6 Effect of Ethanol Content of Fuel on BSPM Emissions at 1,500 rpm........................ 10

$7 \quad$ Effect of Ethanol Content of Fuel on BSPM Emissions at 1,320 rpm........................ 10

8 Contour Plot Showing the Effect of 10\% Ethanol on BSPM Emissions ...................... 11

9 Top View of Figure 8 Showing Regions of Increase and Decrease in BSPM Emissions for Fuel Containing 10\% Ethanol ................................................. 11

10 Contour Plot Showing the Effect of 15\% Ethanol on BSPM Emissions ....................... 13

11 Top View of Figure 10 Showing Regions of Increase and Decrease in BSPM Emissions for Fuel Containing 15\% Ethanol .......................................... 13

12 Effect of Ethanol Content of Fuel on $\mathrm{BSNO}_{\mathrm{x}}$ Emissions at 3,000 rpm ....................... 14

13 Effect of Ethanol Content of Fuel on $\mathrm{BSNO}_{\mathrm{x}}$ Emissions at 1,500 rpm ...................... 14

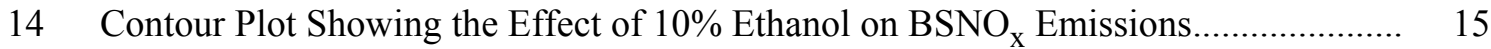

15 Top View of Figure 14 Showing Regions of Increase and Decrease in $\mathrm{BSNO}_{\mathrm{x}}$ Emissions for Fuel Containing 10\% Ethanol............................................. 15

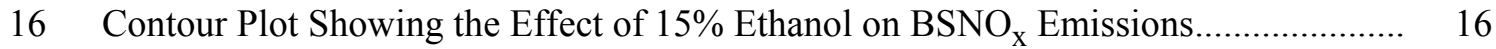

17 Top View of Figure 16 Showing Regions of Increase and Decrease in $\mathrm{BSNO}_{\mathrm{x}}$ Emissions for Fuel Containing 15\% Ethanol............................................ 16

18 Effect of Ethanol Content of Fuel on BSHC Emissions at 3,000 rpm, with $15-\mathrm{Nm}$ Data

19 Effect of Ethanol Content of Fuel on BSHC Emissions at 3,000 rpm, without $15-\mathrm{Nm}$ Data

20 Effect of Ethanol Content of Fuel on BSHC Emissions at 2,000 rpm, with $15-\mathrm{Nm}$ Data

21 Effect of Ethanol Content of Fuel on BSHC Emissions at 2,000 rpm, without $15-\mathrm{Nm}$ Data.

22 Effect of Ethanol Content of Fuel on BSHC Emissions at 1,500 rpm

23 Effect of Ethanol Content of Fuel on BSHC Emissions at 1,320 rpm

Figures (Cont.) 
24 Contour Plot Showing the Effect of $10 \%$ Ethanol on BSHC Emissions

25 Top View of Figure 24 Showing Regions of Increase and Decrease in BSHC Emissions for Fuel Containing 10\% Ethanol

26 Contour Plot Showing the Effect of $15 \%$ Ethanol on BSHC Emissions

27 Top View of Figure 26 Showing Regions of Increase and Decrease in BSHC Emissions for Fuel Containing 15\% Ethanol

28 Effect of Ethanol Content of Fuel on BSCO Emissions at 3,000 rpm, with 15-Nm Data.....

29 Effect of Ethanol Content of Fuel on BSCO Emissions at 3,000 rpm, without 15-Nm Data.

31 Contour Plot Showing the Effect of 10\% Ethanol on BSCO Emissions ..

32 Top View of Figure 31 Showing Regions of Increase and Decrease in BSCO Emissions for Fuel Containing 10\% Ethanol

33 Contour Plot Showing the Effect of 15\% Ethanol on BSCO Emissions

34 Top View of Figure 33 Showing Regions of Increase and Decrease in BSCO Emissions for Fuel Containing 15\% Ethanol

35 Emissions at 800-rpm Idle

\section{Tables}

1 Properties of Phillips Low-Sulfur Diesel Fuel with and without Ethanol and Additives

2 Matrix Points at Which Large Variations in PM Measurements Were Found .......

A.1 Fuel Consumption Data

A.2 Particulate Matter Emissions Data

A.3 Nitrogen Oxides Emissions Data 
$\Delta$

\section{Tables (Cont.)}

A.5 Carbon Monoxide Emissions Data …............................................................... 41

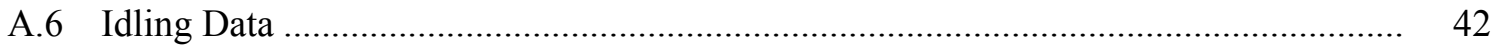




\section{Acknowledgments}

The tests discussed in this report were performed at the AutoResearch Laboratories, Inc., facility in Harvey, Illinois. We thank John D'Auben, David Bell, and Barbara Berzines of the AutoResearch Laboratories staff for their contributions.

Funding for AutoResearch Laboratories was provided by the State of Illinois, Department of Commerce and Community Affairs. We thank David Loos and Norman J. Marek for their support.

Funding for Argonne National Laboratory was provided by the U.S. Department of Energy, Office of Advanced Automotive Technology, under Contract W-31-109-Eng-38. We thank John Garbak for his support. 
$\Delta$ 


\section{Abstract}

Engine-out emissions from a Volkswagen model TDI engine were measured for three different fuels: neat diesel fuel, a blend of diesel fuel and additives containing $10 \%$ ethanol, and a blend of diesel fuel and additives containing $15 \%$ ethanol. The test matrix covered five speeds from 1,320 to $3,000 \mathrm{rpm}$, five torques from $15 \mathrm{Nm}$ to maximum plus the 900 -rpm idle condition, and most of the points in the FTP-75 and US-06 vehicle tests. Emissions of particulate matter (PM), nitrogen oxides $\left(\mathrm{NO}_{\mathrm{x}}\right)$, unburned hydrocarbons ( $\left.\mathrm{HCs}\right)$, and carbon monoxide $(\mathrm{CO})$ were measured at each point, as were fuel consumption, exhaust oxygen, and carbon dioxide output.

PM emissions were reduced up to $75 \%$ when ethanol-diesel blends were used instead of neat diesel fuel. Significant reductions in PM emissions occurred over one-half to two-thirds of the test matrix. $\mathrm{NO}_{\mathrm{x}}$ emissions were reduced by up to $84 \%$. Although the regions of reduced $\mathrm{NO}_{\mathrm{x}}$ emissions were much smaller than the regions of reduced PM emissions, there was considerable overlap between the two regions where $\mathrm{PM}$ emissions were reduced by up to $75 \%$ and $\mathrm{NO}_{\mathrm{x}}$ emissions were reduced by up to $84 \%$. Such simultaneous reduction of both $\mathrm{PM}$ and $\mathrm{NO}_{\mathrm{x}}$ emissions would be difficult to achieve by any other means.

$\mathrm{HC}$ and $\mathrm{CO}$ emissions were also reduced in the regions of reduced $\mathrm{PM}$ and $\mathrm{NO}_{\mathrm{x}}$ emissions that overlapped. Because the ethanol-diesel blends contain less energy on both a per-unit-mass basis and a per-unit-volume basis, there was a reduction in maximum torque of up to $10 \%$ and an increase in brake-specific fuel consumption of up to $7 \%$ when these blends were used. 
$\Delta$ 


\section{Section 1 Introduction}

In the 1980s and early 1990s, there was considerable interest in using ethanol and methanol as the primary fuel for diesel engines (Moses et al. 1980; Toepel et al. 1983; Bechtold et al. 1991). Although these engines produced a significantly smaller amount of particulate matter (PM) emissions than did engines fueled with neat diesel fuel, the disadvantages outweighed the advantages. The engines required modifications, such as a higher compression ratio and fuel injectors with a larger volumetric delivery. They were hard to start and did not always run well at light loads. Starting aids and cetane enhancers were required. Fuel economy was poor because the heat of combustion of alcohol is much less than that of diesel fuel.

More recently, interest has turned to using blends of diesel fuel with oxygenated compounds, including alcohols, as a way to decrease PM emissions from diesel engines (Shih 1998; Ahmed and Marek 1999). Shih tested seven additives and noted that the blend containing $20 \%$ ethanol was one of two fuels that produced the greatest reduction in smoke opacity. He noted a reduction in nitrogen oxides $\left(\mathrm{NO}_{\mathrm{x}}\right)$ emissions at light loads and low speeds. The $\mathrm{NO}_{\mathrm{x}}$ reduction may have been due to a lower cylinder charge temperature and a more homogeneous fuel distribution in the cylinder. He also observed increased unburned hydrocarbon (HC) emissions, which he suggested were a result of bulk quenching at low equivalence ratios. In addition, the lower combustion and exhaust temperatures may have suppressed oxidation of the HCs in the cylinder and exhaust pipe. Shih did not report carbon monoxide (CO) emissions.

Ahmed and Marek reported on fleet testing of ethanol-diesel blends. The three fleets were (1) logging trucks in Sweden; (2) two Mack trucks tested at Archer Daniels Midland Corporation in Decatur, Illinois; and (3) 15 Chicago Transit Authority buses. The Swedish fuel consisted of $15 \%$ hydrated ethanol (containing 5-6\% water) and $0.6 \%$ micro-emulsifying agent, with the balance being diesel fuel. It required mechanical emulsification and produced a fuel that was milky white in color. The American fuel used by the two other fleets consisted of $15 \%$ anhydrous ethanol and 2-5\% additives splash-blended with diesel fuel. It was similar to one of the fuels tested for this report and described below, and it had the color of ordinary diesel fuel. Ahmed and Marek were mainly concerned with fleet operation details and did not report detailed emissions measurements.

In the series of tests done for this report and described below, a 1.9-liter Volkswagen model TDI industrial diesel engine was tested by using fuels containing various quantities of ethanol. Emissions of $\mathrm{PM}, \mathrm{NO}_{\mathrm{x}}, \mathrm{HC}$, and $\mathrm{CO}$ were measured and are reported on here. Fuel consumption and unconsumed oxygen $\left(\mathrm{O}_{2}\right)$ were also measured.

The measured data were validated, and the results showed that under certain operating conditions, $\mathrm{PM}, \mathrm{NO}_{\mathrm{x}}, \mathrm{HC}$, and $\mathrm{CO}$ emissions can be reduced by using ethanol-containing fuel rather than neat diesel fuel. The results also showed that emissions of these pollutants can be 
$\Delta$

simultaneously reduced through the addition of ethanol to the fuel. Tables with details on test results on fuel consumption and emissions are provided in the appendix to this report. 


\section{Section 2 \\ Description of Tests}

The test engine was a 1997 1.9-liter Volkswagen model TDI industrial diesel engine with direct injection, a turbocharger, exhaust-gas recirculation (EGR), and an oxidation catalyst. The engine used the standard engine control unit (ECU) to control fuel injection, EGR, and the turbocharger waste gate.

The engine was tested on a matrix of five speeds and five torques with three different fuels. The test speeds were 1,320, 1,500, 2,000, 2,500, and 3,000 revolutions per minute (rpm). The torques were $15,60.4,105.6$, and 165.9 Newton meters $(\mathrm{Nm})$, and maximum torque. The fuels tested were No. 2 diesel, No. 2 diesel containing additives and 10\% ethanol, and No. 2 diesel containing additives and 15\% ethanol. Properties of the fuels are shown in Table 1. The ethanol and additives were provided by Pure Energy Corporation and were splash-blended with the diesel fuel. The test matrix, shown in Figure 1, covers nearly all of the points in U.S. Environmental Protection Agency (EPA) test procedure FTP-75 and federal test procedure US-06. The engine was also tested at idle $(900 \mathrm{rpm})$ for each of the three fuels.

Gaseous exhaust emissions $\left(\mathrm{NO}_{\mathrm{x}}, \mathrm{HC}, \mathrm{CO}\right.$, carbon dioxide $\left[\mathrm{CO}_{2}\right]$, and $\mathrm{O}_{2}$ ) were measured at each point in the matrix. PM emissions were measured three times at each point in the matrix. All of the emissions data were collected engine out (i.e., upstream of the catalyst). Gaseous emissions were delivered via a heated line to a Horiba emissions bench. Particulate emissions were collected through a mini-dilution tunnel onto a filter.

All measurements were corrected for barometric pressure and exhaust-gas moisture (Society of Automotive Engineers 1995). In addition, the air/fuel (A/F) ratio was computed and compared to its measured value as a validity check on the data.

Table 1 Properties of Phillips Low-Sulfur Diesel Fuel with and without Ethanol and Additives

\begin{tabular}{|lllll|}
\hline \multicolumn{1}{|c}{ Property } & $\begin{array}{c}\text { ASTM } \\
\text { Standard }\end{array}$ & $\begin{array}{c}\mathbf{0 \%} \\
\text { Ethanol }\end{array}$ & $\begin{array}{c}\mathbf{1 0 \%} \\
\text { Ethanol }\end{array}$ & $\begin{array}{c}\mathbf{1 5 \%} \\
\text { Ethanol }\end{array}$ \\
\hline Lower heating value (MJ/kg) & $\mathrm{D} 240$ & 43.37 & 42.00 & 41.61 \\
Carbon (wt \%) & $\mathrm{D} 5291$ & 86.88 & 84.27 & 82.41 \\
Hydrogen (wt \%) & $\mathrm{D} 5291$ & 13.12 & 13.18 & 13.55 \\
Oxygen (wt \%) & $\mathrm{D} 5291$ & 0.04 & 2.55 & 4.04 \\
Hydrogen/carbon ratio & & 1.7996 & 1.8638 & 1.9594 \\
Stoichiometric air/fuel ratio & & 14.498 & 14.590 & 14.726 \\
\hline
\end{tabular}




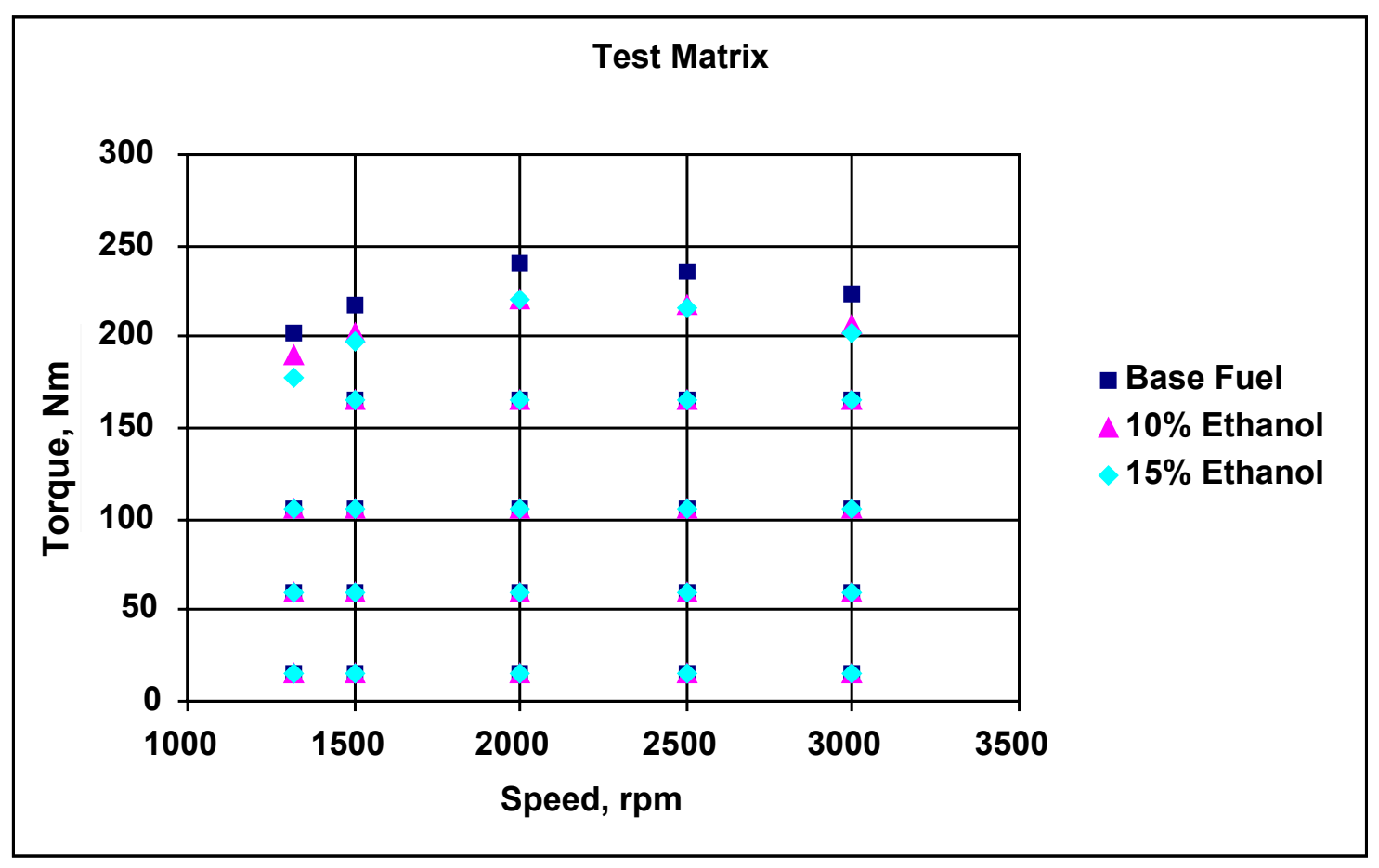

Figure 1 Test Matrix 


\section{Section 3 Test Results}

\subsection{Validity of Data}

At five points on the test matrix, the three measured PM values (i.e., one for each fuel) showed large variations. These are shown in Table 2. In every case, the first PM measurement showed the largest deviation from the average of the three measurements. The most likely explanation is that the engine and instruments had not fully stabilized before the sample was obtained. Therefore, the first PM measurement at each of the five matrix points was declared invalid, and the second and third measurements were averaged to produce the reported PM measurement. For all other matrix points, all three of the PM measurements were considered valid, so all three were averaged to produce the reported PM measurement. The result is that valid PM measurements were obtained at each point on the test matrix.

\section{Table 2 Matrix Points at Which Large Variations in PM Measurements Were Found}

\begin{tabular}{|ccc|}
\hline $\begin{array}{c}\text { Speed } \\
\text { (rpm) }\end{array}$ & $\begin{array}{c}\text { Torque } \\
\text { (Nm) }\end{array}$ & $\begin{array}{c}\text { Ethanol } \\
\text { Quantity (\%) }\end{array}$ \\
\hline & & 0 \\
3,000 & 15 & 0 \\
2,500 & 15 & 0 \\
1,500 & 15 & 10 \\
1,320 & 15 & 15 \\
3,000 & 202.8 (maximum) \\
\hline
\end{tabular}

\subsection{Particulate Emissions on the Test Matrix}

Figure 2 shows the effect of the ethanol content of fuel on the brake-specific PM (BSPM) emissions at 3,000 rpm. At this speed, the BSPM levels at $15 \mathrm{Nm}$ are far greater than the BSPM levels at other torques and dominate the scale of the plot. There is considerable variation in the $15-\mathrm{Nm}$ curve for different amounts of ethanol in the fuel. When $10 \%$

ethanol is used, $73 \%$ less PM is emitted than when ethanol-free fuel is used, but when $15 \%$ ethanol is used, $18 \%$ more PM is emitted than when ethanol-free fuel is used.

Figure 3 is the same as Figure 2, except that the 15-Nm data have been deleted and the scale of BSPM has been expanded. Figure 3 shows the effect of ethanol content on BSPM emissions at higher torques. At lower torques, adding ethanol to the fuel increases BSPM levels, but at the maximum torque, adding ethanol to the fuel decreases BSPM levels; a similar effect can be seen at 2,500 rpm in Figure 4.

In Figure 5 (2,000 rpm), the 15-Nm torque curve can be shown without obscuring the other data. Adding ethanol at medium and high torques decreases BSPM emissions. The same effect can be seen in Figures 6 (1,500 rpm) and 7 (1,320 rpm).

Figure 8 shows a contour plot of the percentage increase in BSPM emissions with the addition of $10 \%$ ethanol to the fuel. Decreases in BSPM levels are shown as negative numbers on the plot. This figure shows that there are regions of increase and decrease in BSPM levels. Figure 9, a top view of Figure 8, shows the regions in which BSPM emissions increase on the 


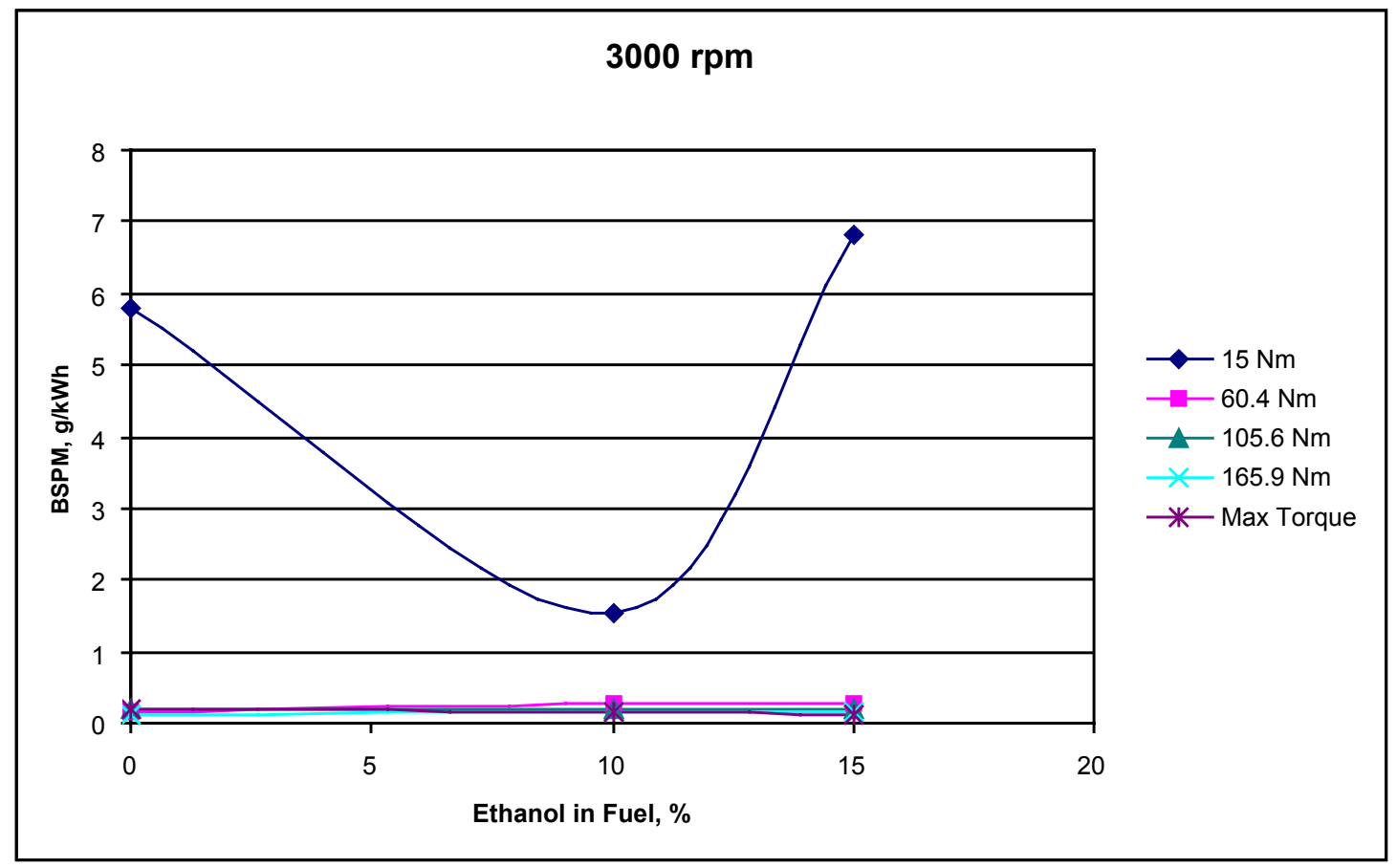

Figure 2 Effect of Ethanol Content of Fuel on BSPM Emissions at 3,000 rpm, with 15-Nm Torque Data

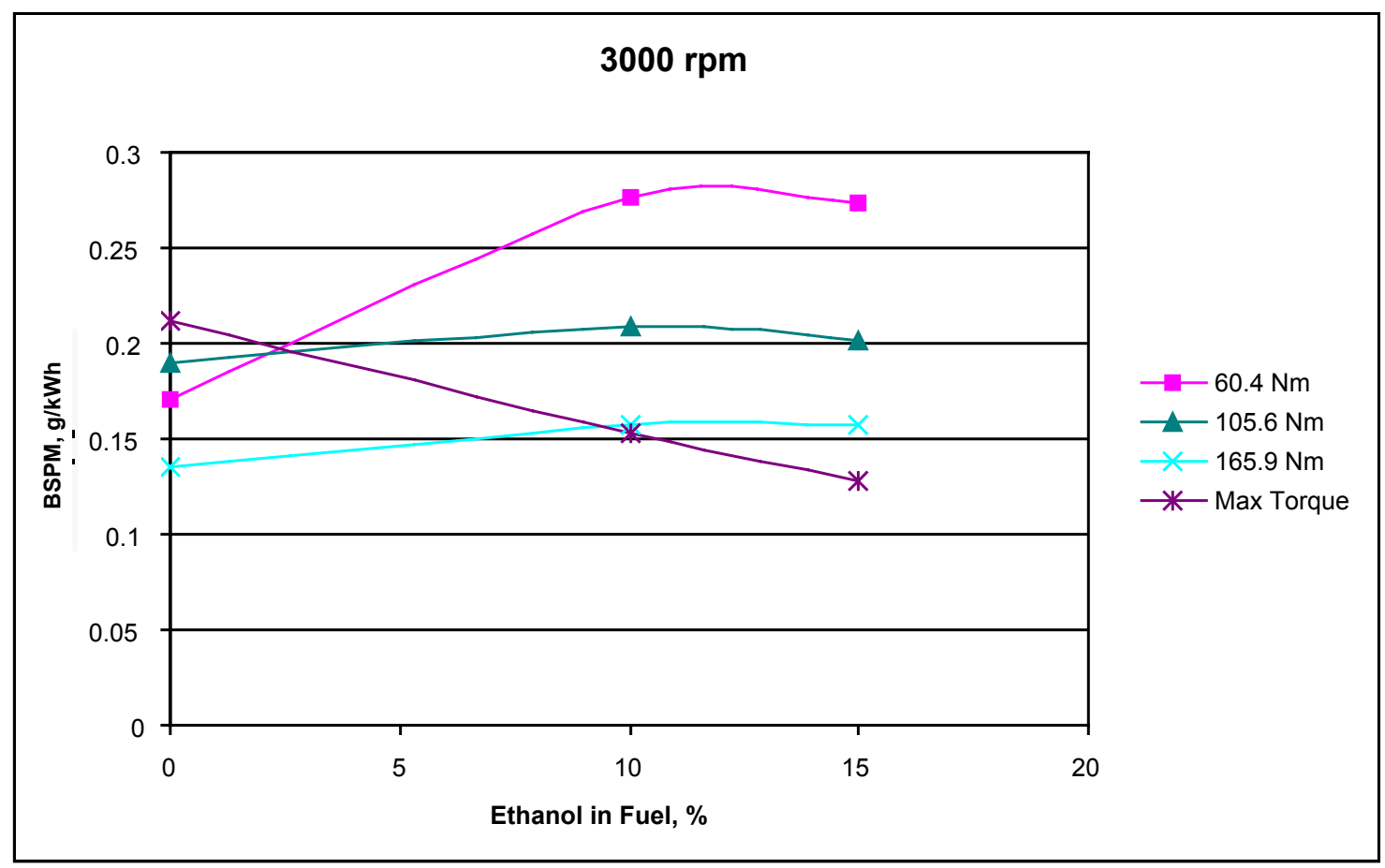

Figure 3 Effect of Ethanol Content of Fuel on BSPM Emissions at 3,000 rpm, without 15-Nm Torque Data 


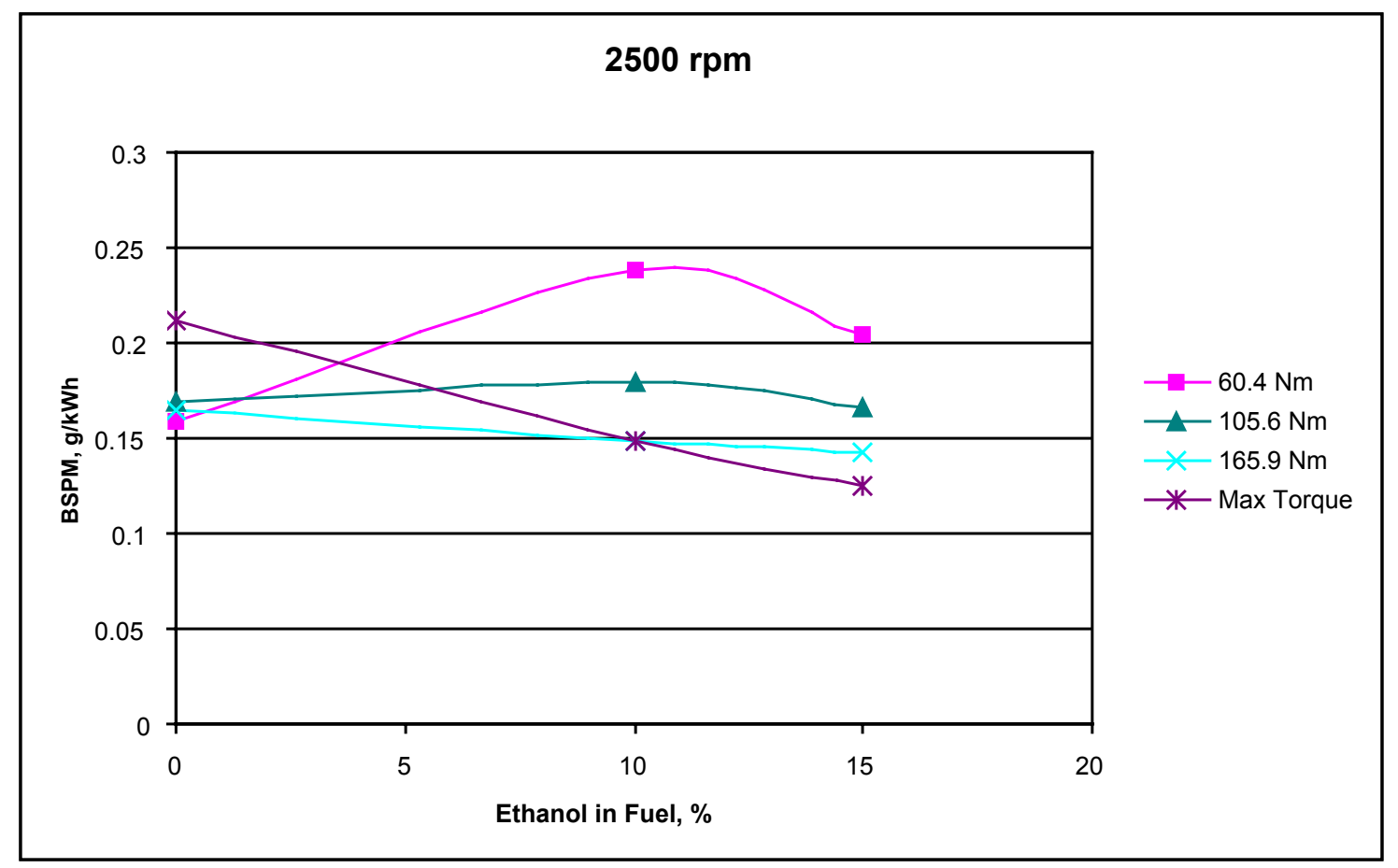

Figure 4 Effect of Ethanol Content of Fuel on BSPM Emissions at 2,500 rpm

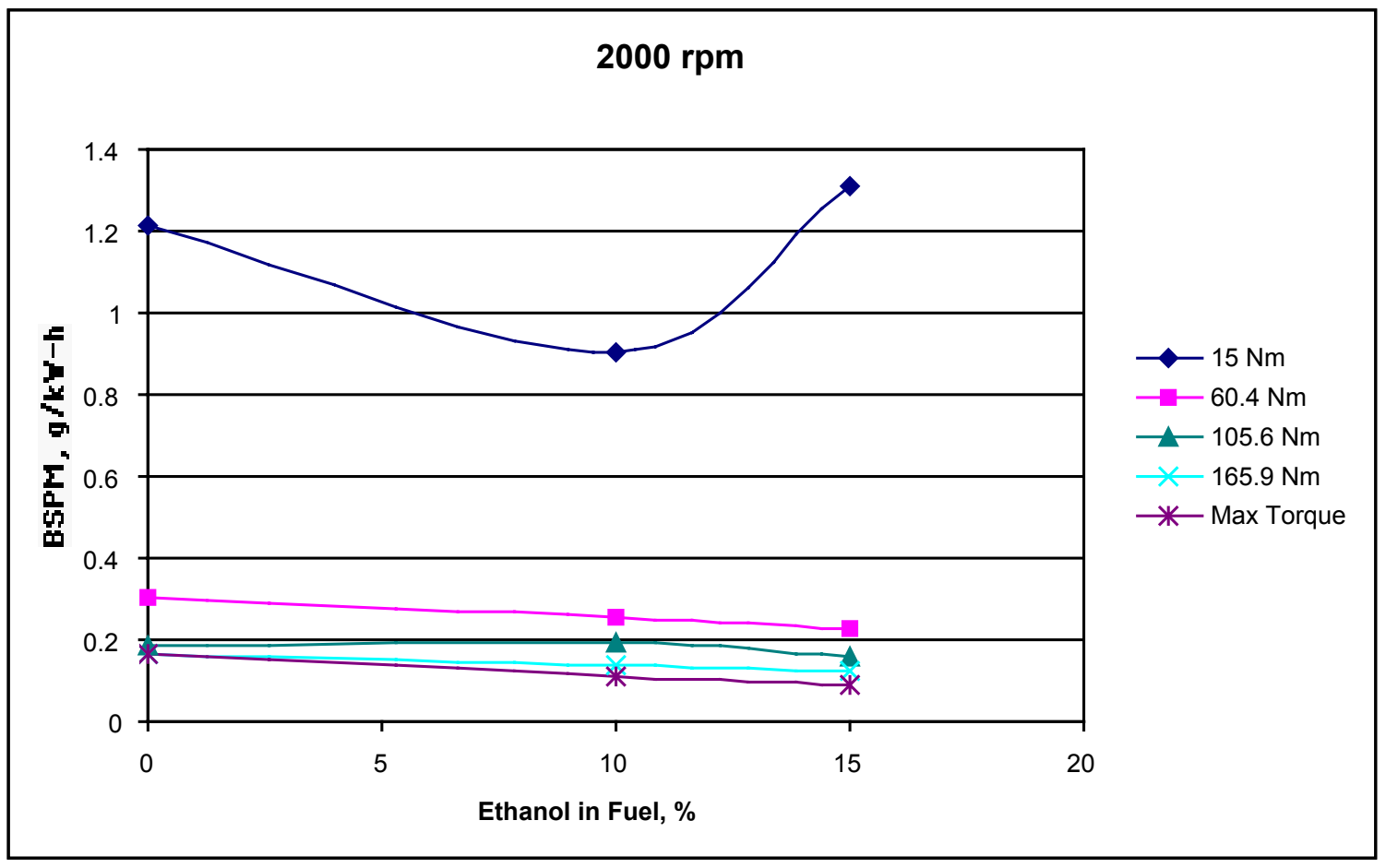

Figure 5 Effect of Ethanol Content of Fuel on BSPM Emissions at 2,000 rpm 


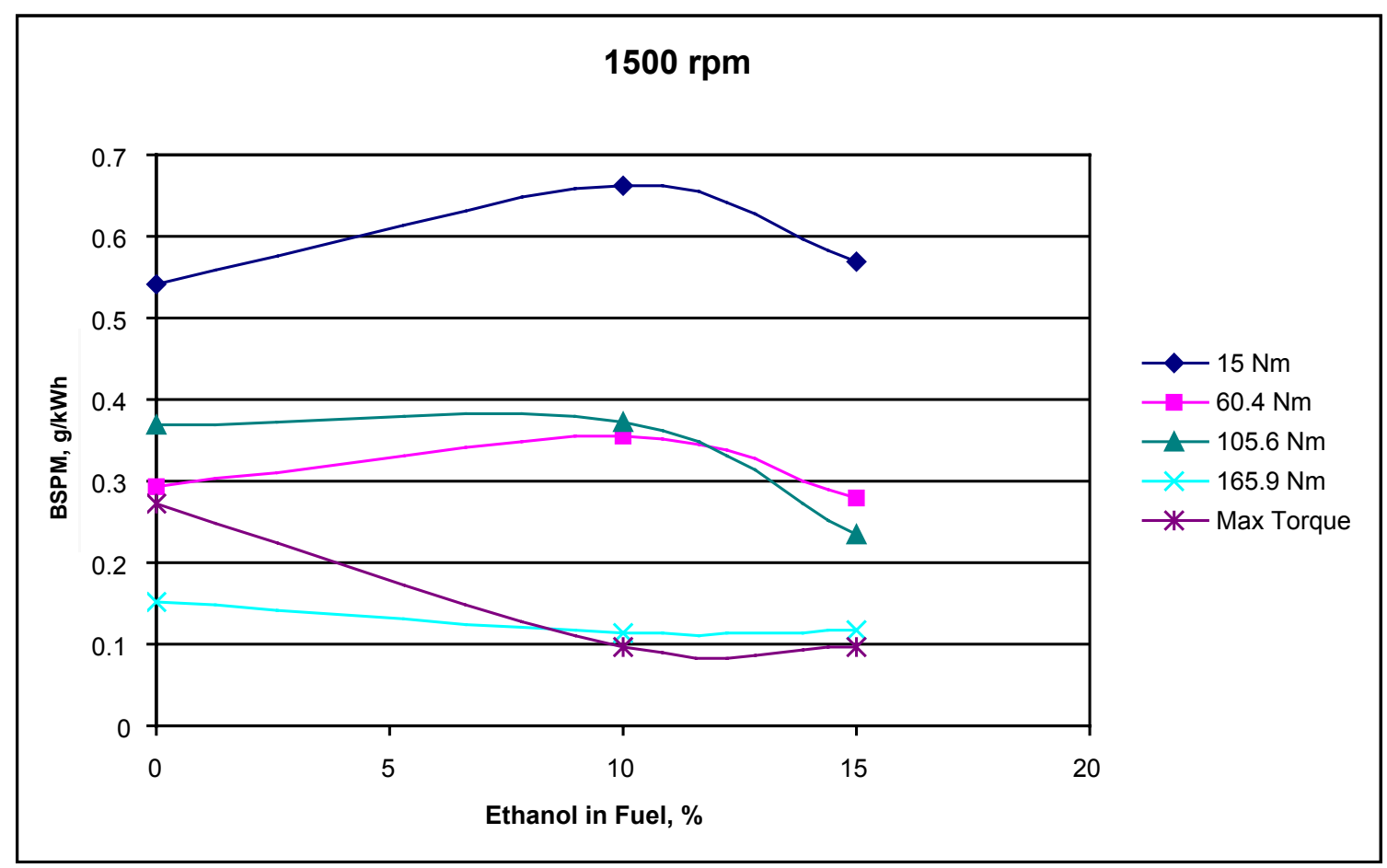

Figure 6 Effect of Ethanol Content of Fuel on BSPM Emissions at 1,500 rpm

Figure 7 Effect of Ethanol Content of Fuel on BSPM Emissions at 1,320 rpm

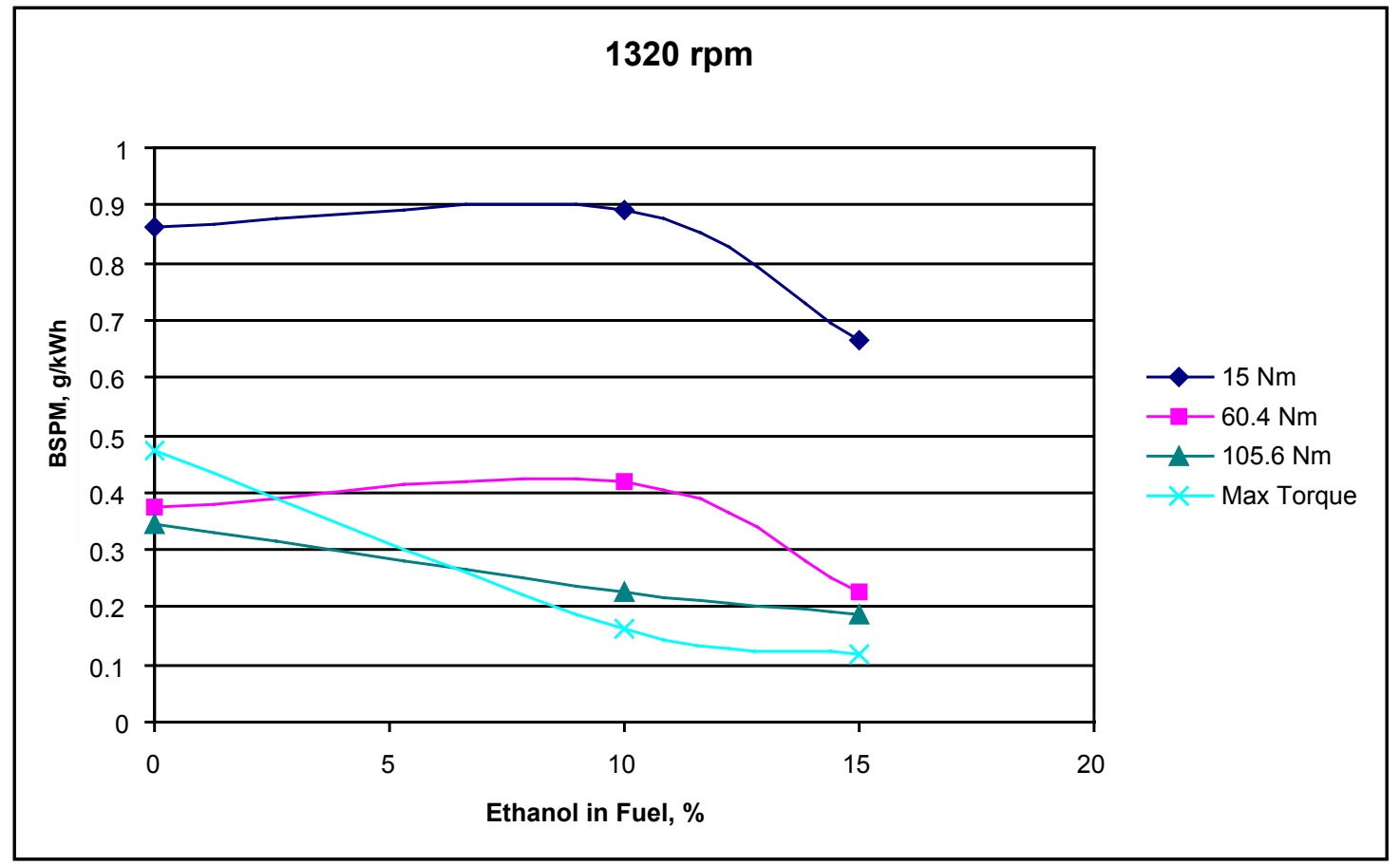




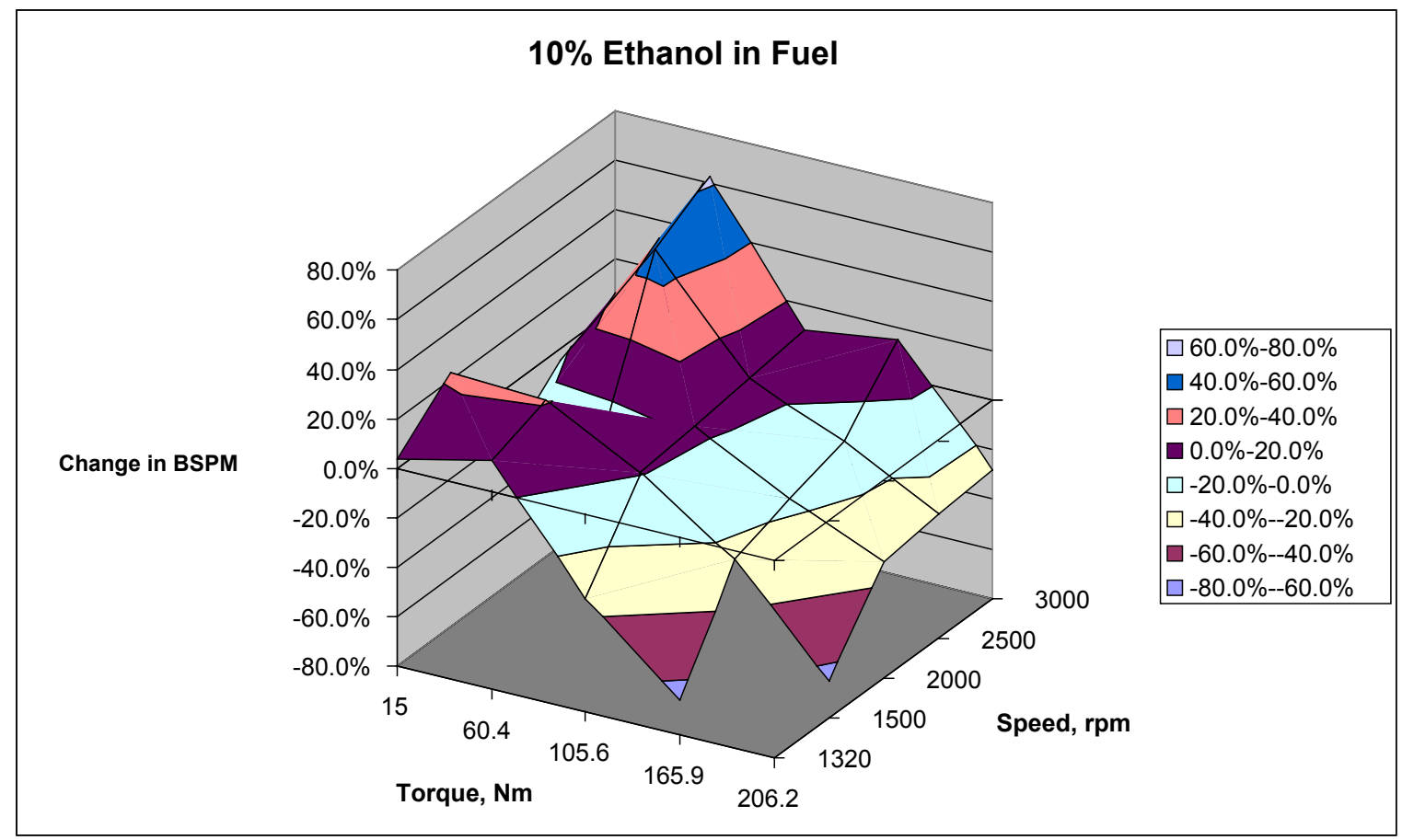

Figure 8 Contour Plot Showing the Effect of $10 \%$ Ethanol on BSPM Emissions

\section{Change in BSPM, 10\% Ethanol in Fuel}

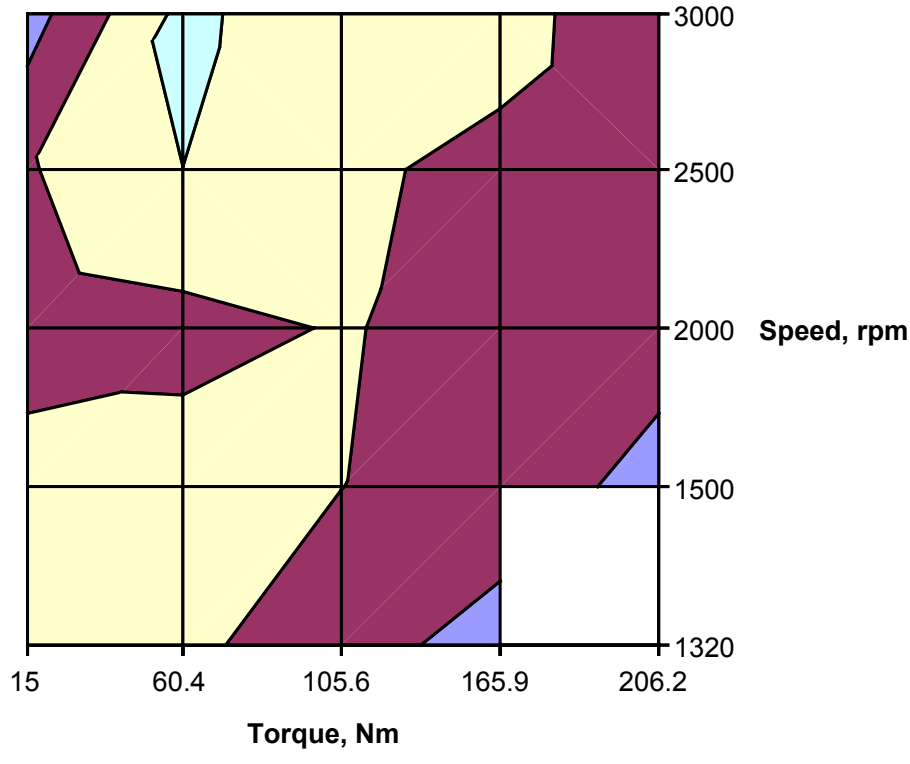

\begin{tabular}{|l|}
\hline $50.0 \%-100.0 \%$ \\
0.0\%-50.0\% \\
-50.0\%-0.0\% \\
-100.0\%--50.0\%
\end{tabular}

Figure 9 Top View of Figure 8 Showing Regions of Increase (Light) and Decrease (Dark) in BSPM Emissions for Fuel Containing 10\% Ethanol 
test matrix as lighter shades and the regions in which BSPM emissions decrease as darker shades. A substantial region of decrease in BSPM emissions occurs at the higher torque levels at all speeds. This decrease is desirable for heavy-duty trucks, which tend to operate at higher loads (relative to the size of the engine) than do automobiles.

Figure 10 shows a contour plot of the percentage increase in BSPM emissions with the addition of $15 \%$ ethanol to the fuel. As occurs in Figure 8, decreases in BSPM are shown as negative numbers on the plot. This figure shows a larger region of decrease in BSPM emissions than is shown in Figure 8. Figure 11 is a top view of Figure 10. Like Figure 9, regions in which BSPM emissions increase are shown as lighter shades, and regions in which BSPM decrease are shown as darker shades. In this figure, the region of BSPM decrease is larger than the corresponding region for $10 \%$ ethanol; here it covers approximately two-thirds of the test matrix.

\subsection{Nitrogen Oxides Emissions on the Test Matrix}

Figure 12 shows the effect of the ethanol content of the fuel on brake-specific $\mathrm{NO}_{\mathrm{x}}\left(\mathrm{BSNO}_{\mathrm{x}}\right)$ emissions at 3,000 rpm. At the lightest load, $\mathrm{BSNO}_{\mathrm{x}}$ emissions decrease by $20 \%$ when $10 \%$ ethanol is used and by $49 \%$ when $15 \%$ ethanol is used. At the higher loads, $\mathrm{BSNO}_{\mathrm{x}}$ emissions increase by as much as $25 \%$. The trends at 2,500 and 2,000 rpm are similar but are not shown in this report.

Figure 13 shows a reversal of the trends shown in Figure 12. At 1,500 rpm, $\mathrm{BSNO}_{\mathrm{x}}$ emissions decrease at the higher loads by as much as $60 \%$ when $15 \%$ ethanol is used. At lower loads, $\mathrm{BSNO}_{\mathrm{x}}$ emissions decrease by $6-10 \%$ when $10 \%$ ethanol is used and increase by approximately $8 \%$ when $15 \%$ ethanol is used. The trends at $1,320 \mathrm{rpm}$ are similar but are not shown in this report.

Figure 14 shows a contour plot of $\mathrm{BSNO}_{\mathrm{x}}$ emissions versus torque and speed when $10 \%$ ethanol is used. The largest increases in $\mathrm{BSNO}_{\mathrm{x}}$ emissions occur at 165.9-Nm torque and a speed of 2,500 rpm; the region centered on 1,500 rpm shows decreases in $\mathrm{BSNO}_{\mathrm{x}}$ emissions at all torque levels. Figure 15, a top view of Figure 14, confirms these trends. In Figure 15, the dark region centered on $1,500 \mathrm{rpm}$ is where $10 \%$ ethanol in the fuel decreases $\mathrm{BSNO}_{\mathrm{x}}$ emissions.

Figure 16 is a contour plot of $\mathrm{BSNO}_{\mathrm{x}}$ emissions versus torque and speed with $15 \%$ ethanol. As occurs in Figure 14, the largest increase in $\mathrm{BSNO}_{\mathrm{x}}$ emissions occurs at 165.9-Nm torque and a speed of 2,500 rpm, while decreases in $\mathrm{BSNO}_{\mathrm{x}}$ emissions occur above 105.6-Nm torque and below 1,700 rpm. Elsewhere, there are modest increases in $\mathrm{BSNO}_{\mathrm{x}}$ emissions. Figure 17, a top view of Figure 16, confirms these observations. The lightly shaded areas are regions where $\mathrm{BSNO}_{\mathrm{x}}$ emissions increase and the darker areas are regions where $\mathrm{BSNO}_{\mathrm{x}}$ emissions decrease when $15 \%$ ethanol fuel is used.

A comparison of Figure 15 with Figure 9 and of Figure 17 with Figure 11 shows that there is an overlap between the region where PM emissions decrease compared to neat diesel fuel and the region where $\mathrm{NO}_{\mathrm{x}}$ emissions decrease compared to neat diesel fuel. In the overlap region, both $\mathrm{PM}$ emissions and $\mathrm{NO}_{\mathrm{x}}$ emissions decrease simultaneously, by levels of up to $75 \%$ for PM emissions and up to $84 \%$ for $\mathrm{NO}_{\mathrm{x}}$ emissions. 


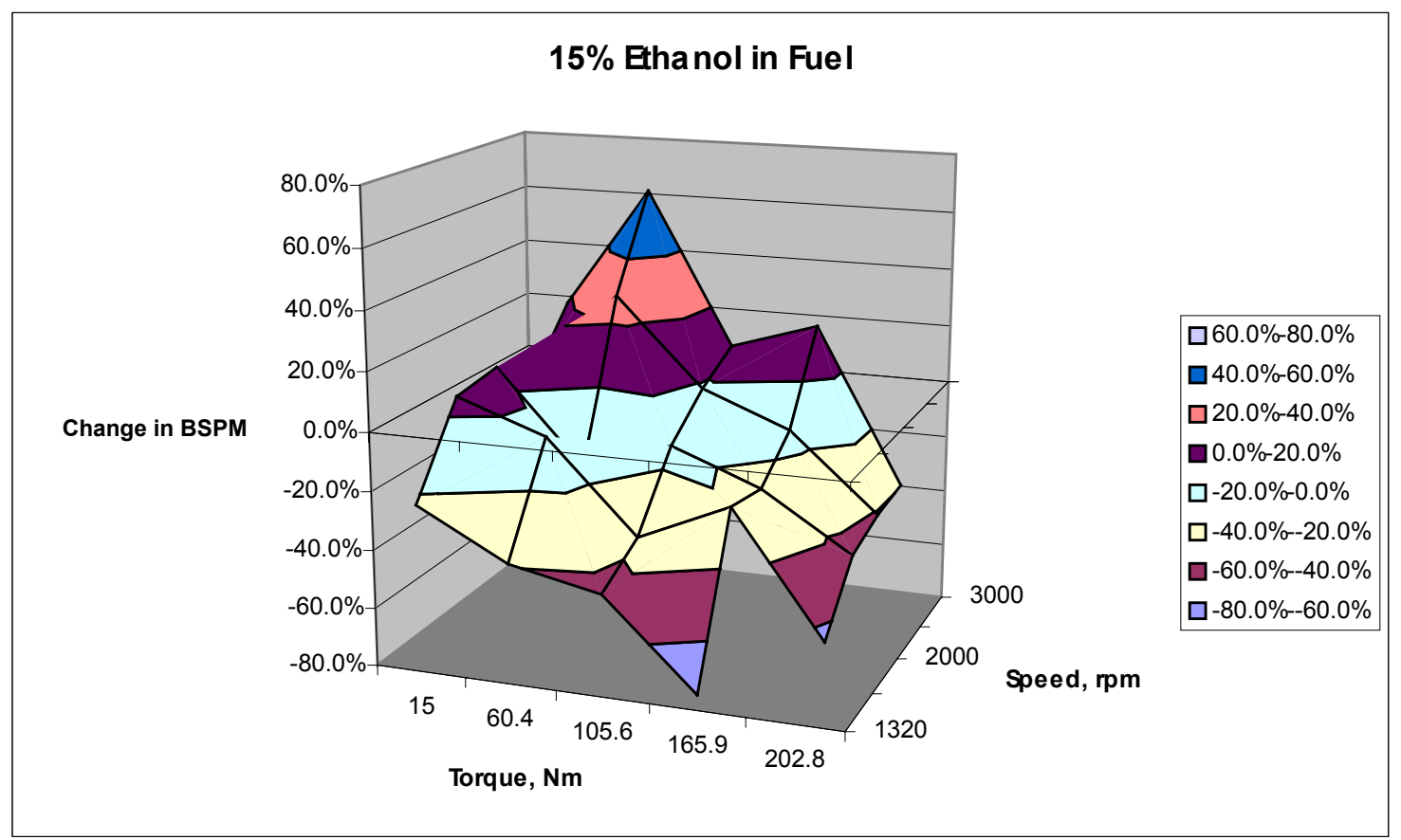

Figure 10 Contour Plot Showing the Effect of 15\% Ethanol on BSPM Emissions

\section{Change in BSPM, 15\% Ethanol in Fuel}
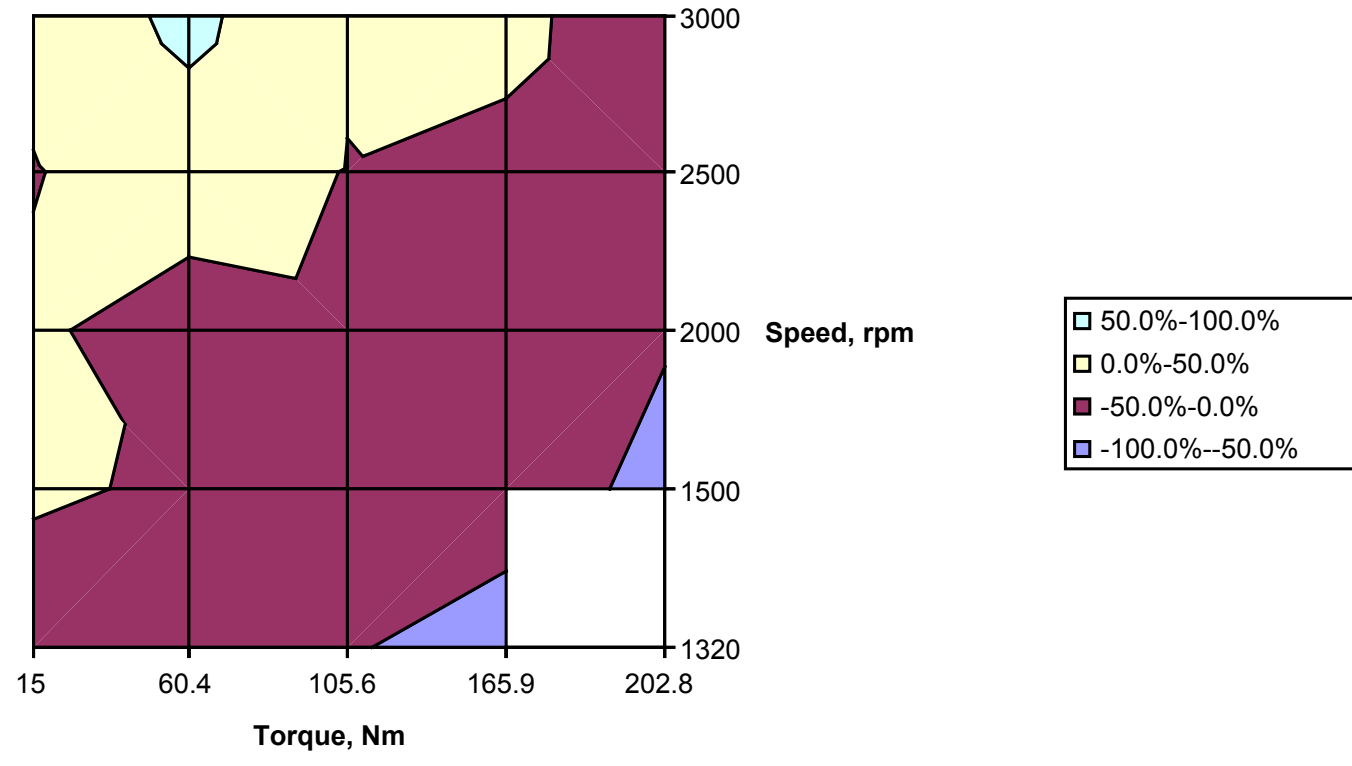

Figure 11 Top View of Figure 10 Showing Regions of Increase (Light) and Decrease (Dark) in BSPM Emissions for Fuel Containing 15\% Ethanol 


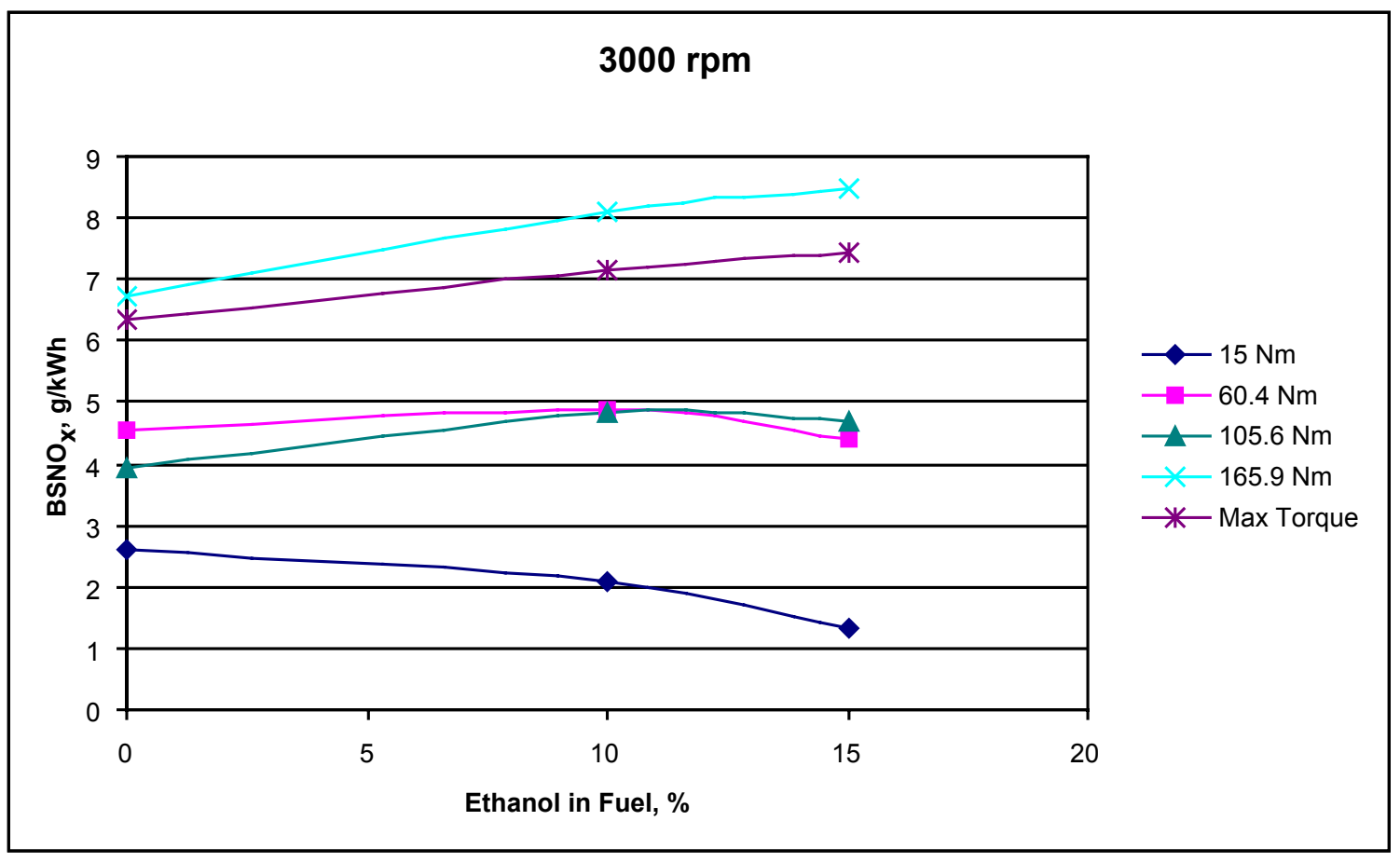

Figure 12 Effect of Ethanol Content of Fuel on $\mathrm{BSNO}_{\mathrm{x}}$ Emissions at 3,000 rpm

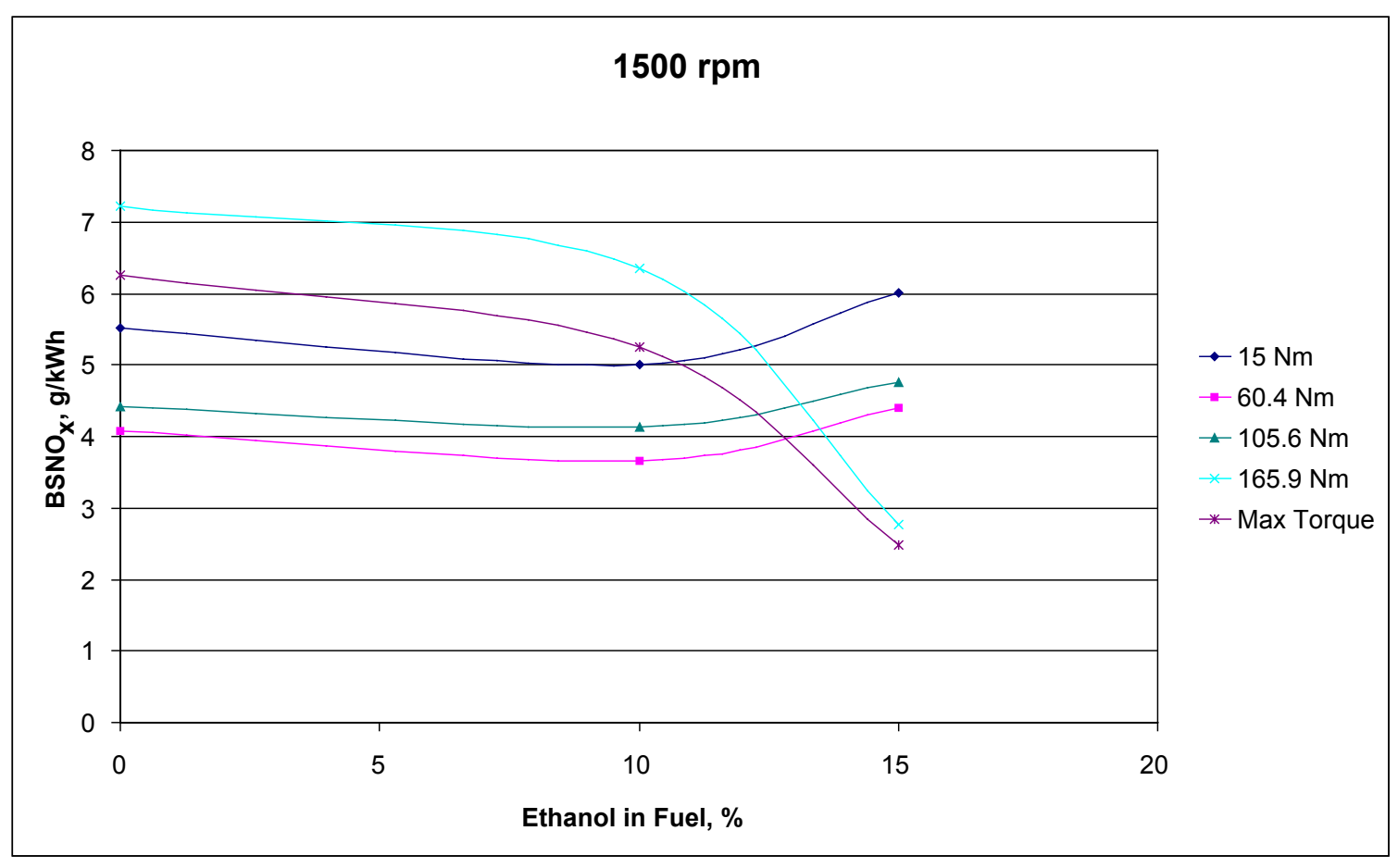

Figure 13 Effect of Ethanol Content of Fuel on $\mathrm{BSNO}_{x}$ Emissions at 1,500 rpm 


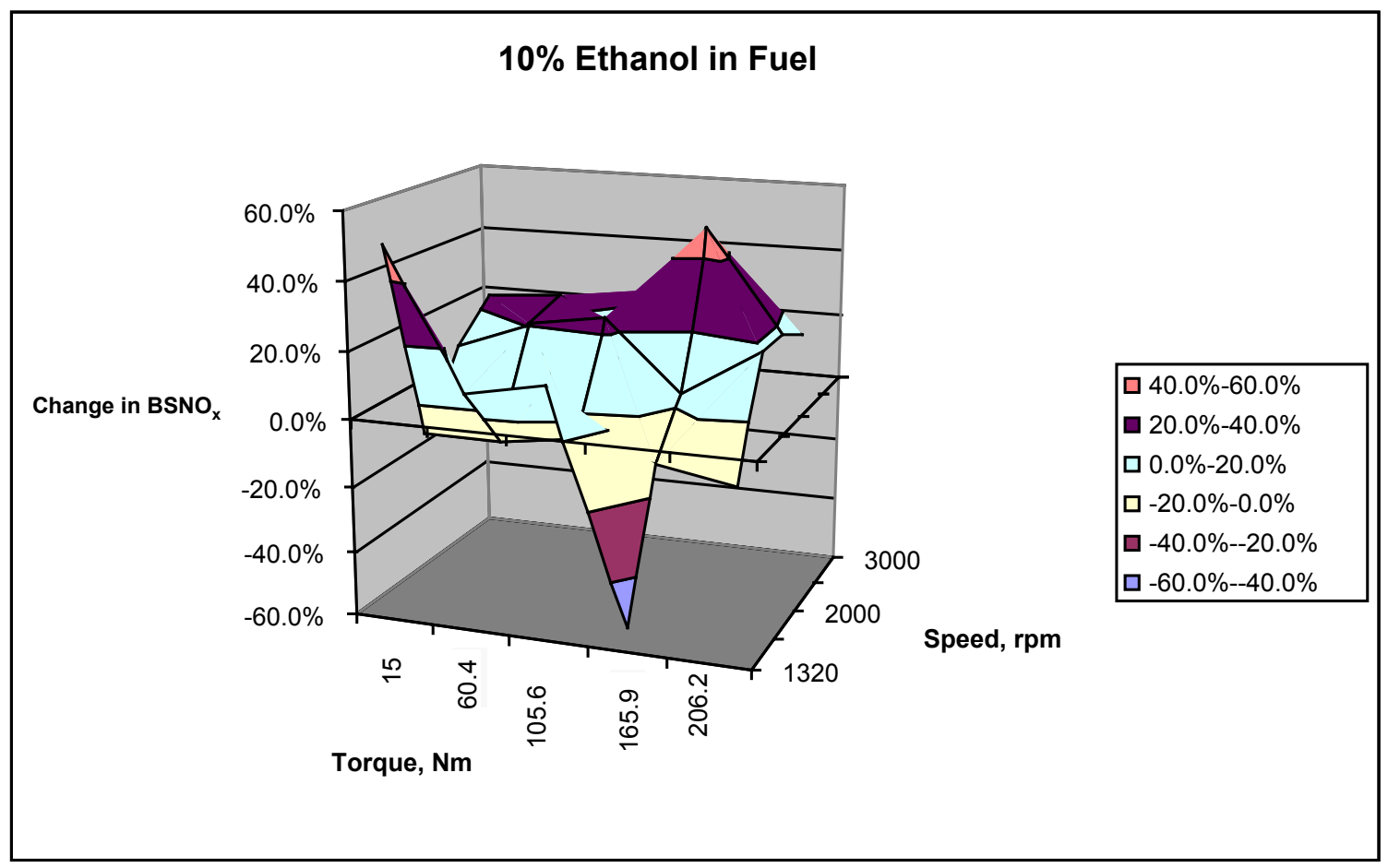

Figure 14 Contour Plot Showing the Effect of $10 \%$ Ethanol on $\mathrm{BSNO}_{\mathrm{x}}$ Emissions

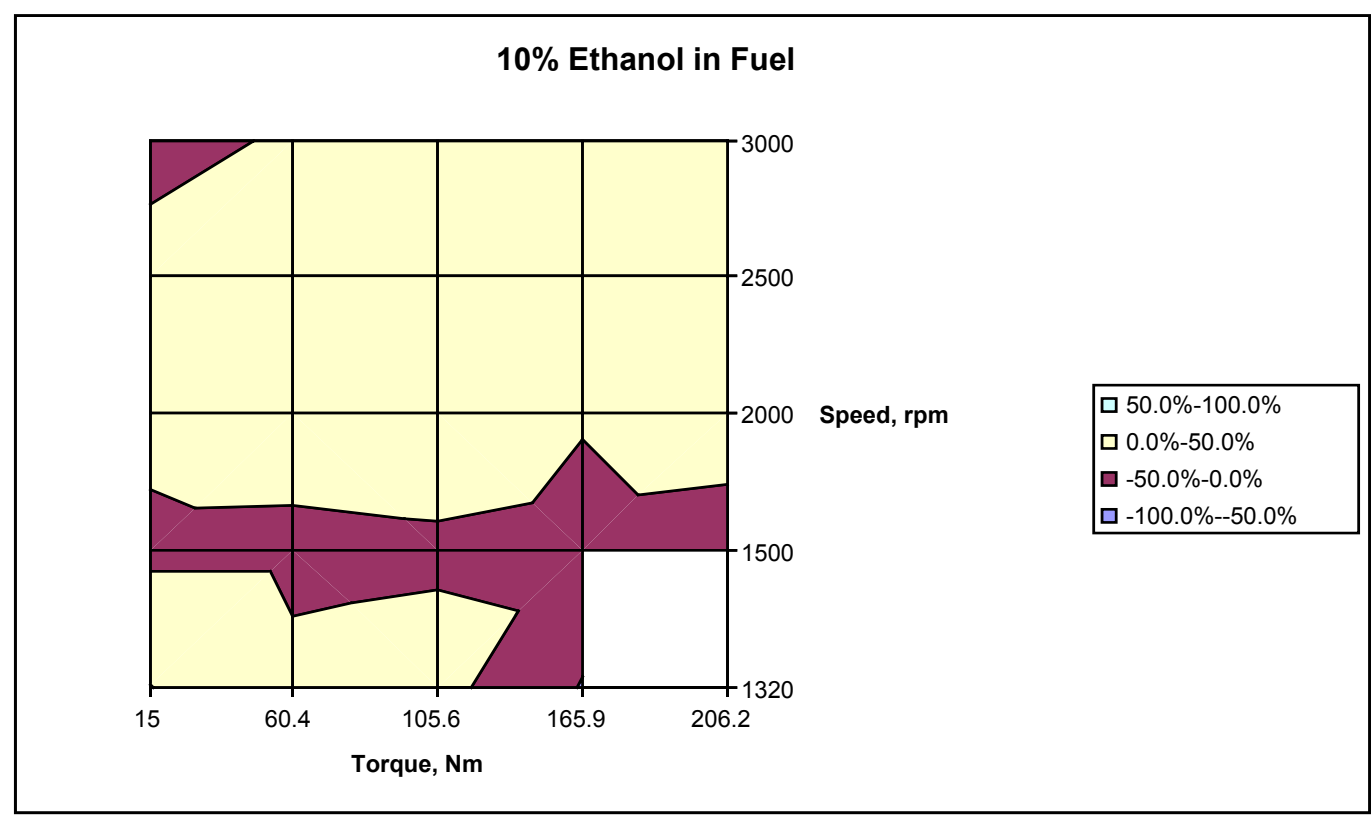

Figure 15 Top View of Figure 14 Showing Regions of Increase (Light) and Decrease (Dark) in $\mathrm{BSNO}_{\mathrm{x}}$ Emissions for Fuel Containing 10\% Ethanol 


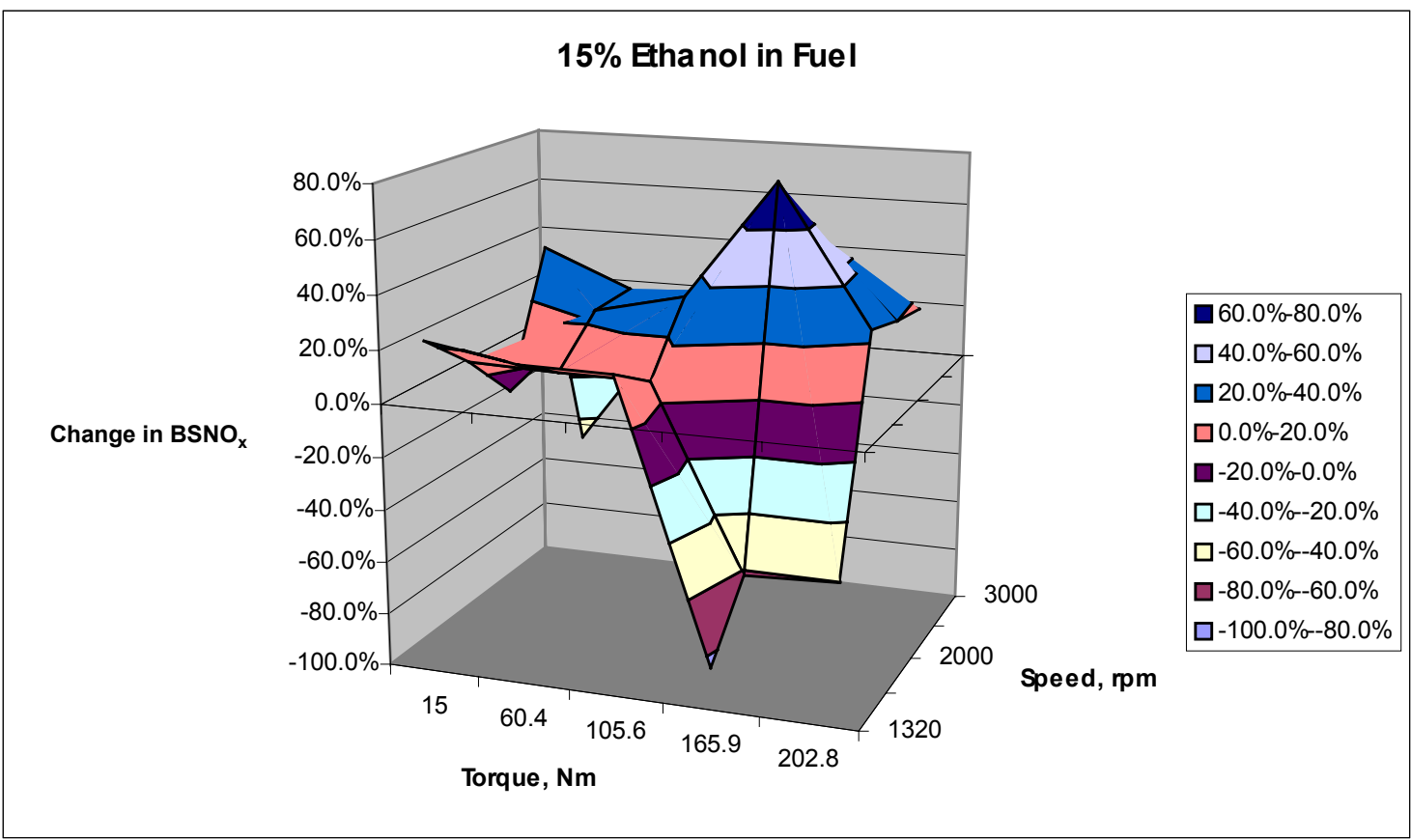

Figure 16 Contour Plot Showing the Effect of 15\% Ethanol on $\mathrm{BSNO}_{\mathrm{x}}$ Emissions

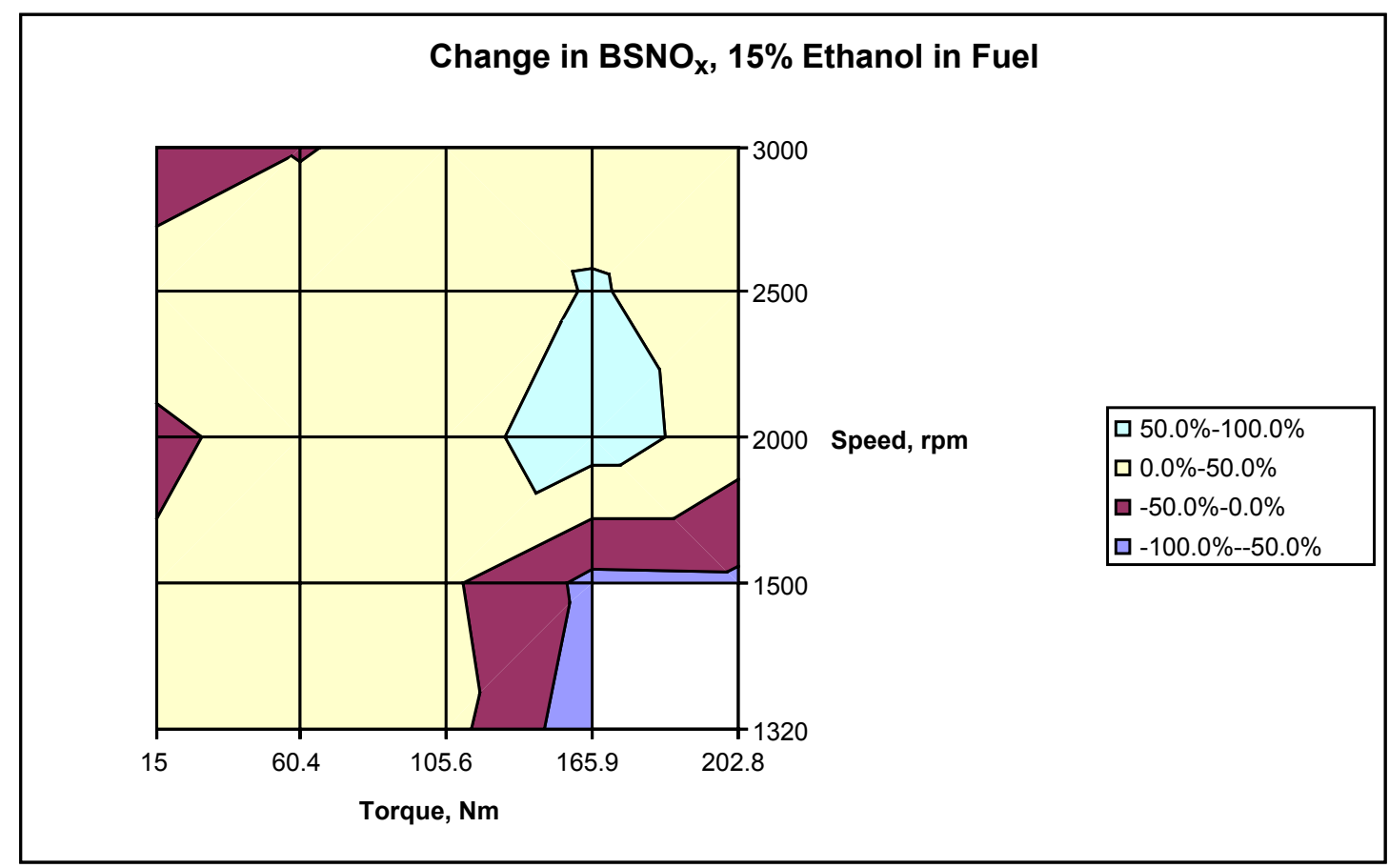

Figure 17 Top View of Figure 16 Showing Regions of Increase (Light) and Decrease (Dark) in $\mathrm{BSNO}_{\mathrm{x}}$ Emissions for Fuel Containing 15\% Ethanol 


\subsection{Hydrocarbon Emissions on the Test Matrix}

Figure 18 shows the effect of the ethanol content of fuel on brake-specific HC (BSHC) emissions at 3,000 rpm. At this speeds the levels of BSHC emissions at $15 \mathrm{Nm}$ are far greater than the BSHC emissions at other torques and dominate the scale of the plot. When $10 \%$ ethanol is used, $42 \%$ less $\mathrm{HC}$ is emitted than when neat diesel fuel is used, but when $15 \%$ ethanol is used, $226 \%$ more $\mathrm{HC}$ is emitted than when neat diesel fuel is used.

Figure 19 is the same as Figure 18, except that the 15-Nm curve has been deleted and the scale of BSHC has been expanded. Figure 19 shows that the shape of the 60.4-Nm curve is similar to the shape of the $15-\mathrm{Nm}$ curve. When $10 \%$ ethanol is used, $11 \%$ less $\mathrm{HC}$ is emitted than when neat diesel fuel is used, but when $15 \%$ ethanol is used, $17 \%$ more $\mathrm{HC}$ is emitted than when neat diesel fuel is used. At the higher torques, the shapes of the curves are different; when $10 \%$ ethanol is used, more $\mathrm{HC}$ is emitted than when neat diesel fuel or the fuel containing $15 \%$ ethanol is used. When $10 \%$ ethanol is used, $63-153 \%$ more $\mathrm{HC}$ is emitted than when neat diesel fuel is used, but when $15 \%$ ethanol is used, only $48-120 \%$ more $\mathrm{HC}$ is emitted than when neat diesel fuel is used. At 2,500 rpm, the trend is similar, except that the $60.4-\mathrm{Nm}$ curve behaves like the curves of the higher torques.

At 2,000 rpm, the shape of the 15-Nm curve changes. Figure 20 shows the effect of the ethanol content of fuel on BSHC emissions at 2,000 rpm. At $15 \mathrm{Nm}$, the BSHC emissions for both $10 \%$ and $15 \%$ ethanol are less than the BSHC emissions for neat diesel fuel.

Figure 21 is the same as Figure 20, except that the 15-Nm curve has been deleted. The $169.5-\mathrm{Nm}$ curve behaves differently than the others and may be anomalous. When $10 \%$ ethanol is used, $247 \%$ more HC is emitted than when neat diesel fuel is used, but when $15 \%$ ethanol is used, $32 \%$ less $\mathrm{HC}$ is emitted than when neat diesel fuel is used. The curves for other torques have the same shape as the high-torque curves for higher speeds.

Figure 22 shows the effect of the ethanol content of fuel on BSHC emissions at 1,500 rpm. The BSHC emission levels for both $10 \%$ and $15 \%$ ethanol for any torque are nearly equal, and both levels are less than the BSHC levels from neat diesel fuel.

Figure 23 shows the effect of the ethanol content of fuel on BSHC emissions at 1,320 rpm. At $15 \mathrm{Nm}$, adding ethanol to the fuel increases the BSHC emissions over those from neat diesel fuel, but at higher torques, adding ethanol to the fuel decreases the BSHC emissions below those from neat diesel fuel.

Figure 24 shows a contour plot of the increase in BSHC emissions for the fuel containing $10 \%$ ethanol compared to neat diesel fuel. There is a region consisting of a band of all torques centered on 1,500 rpm plus another band of all speeds at $15 \mathrm{Nm}$ where BSHC emissions are less for the fuel containing $10 \%$ ethanol than for neat diesel fuel. Along the 1,500-rpm line, the decrease is $58-87 \%$. Along the $15-\mathrm{Nm}$ line, decreases range from $11 \%$ to $85 \%$, with the largest decrease occurring at $1,500 \mathrm{rpm}$. Elsewhere, there is a peak increase of $247 \%$ at $2,000 \mathrm{rpm}$ and $165.9 \mathrm{Nm}$. 


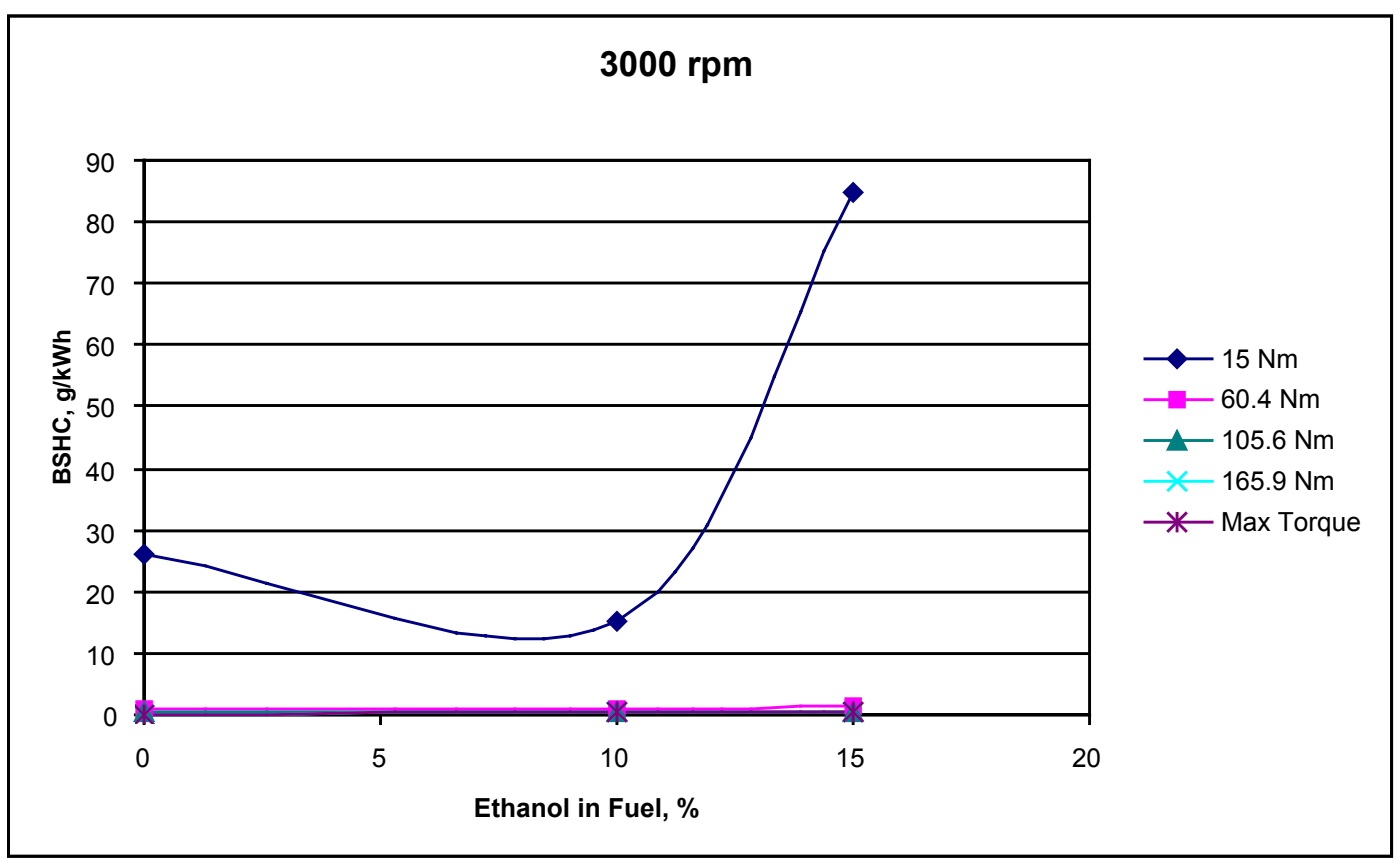

Figure 18 Effect of Ethanol Content of Fuel on BSHC Emissions at 3,000 rpm, with 15-Nm Data

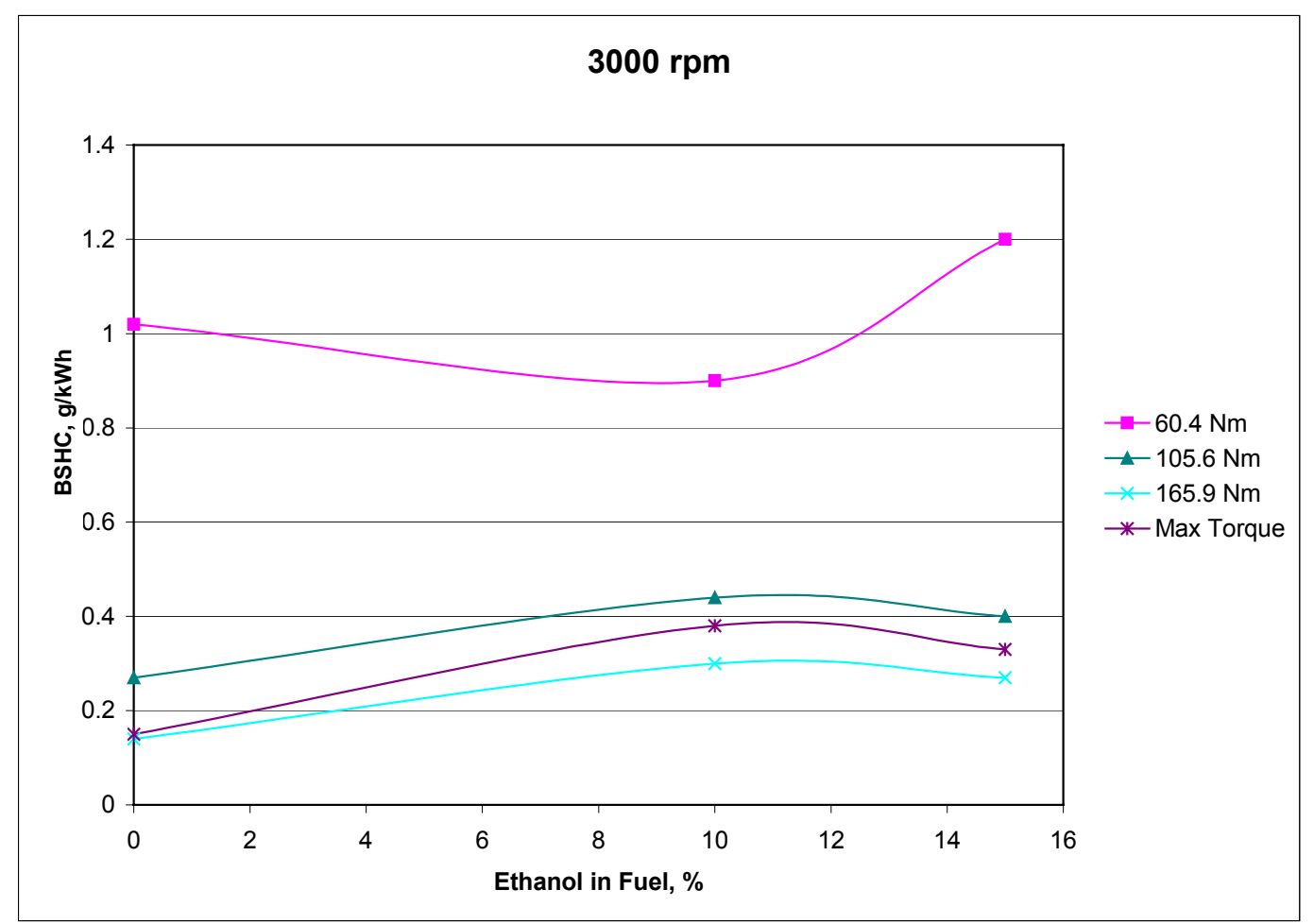

Figure 19 Effect of Ethanol Content of Fuel on BSHC Emissions at 3,000 rpm, without 15-Nm Data 


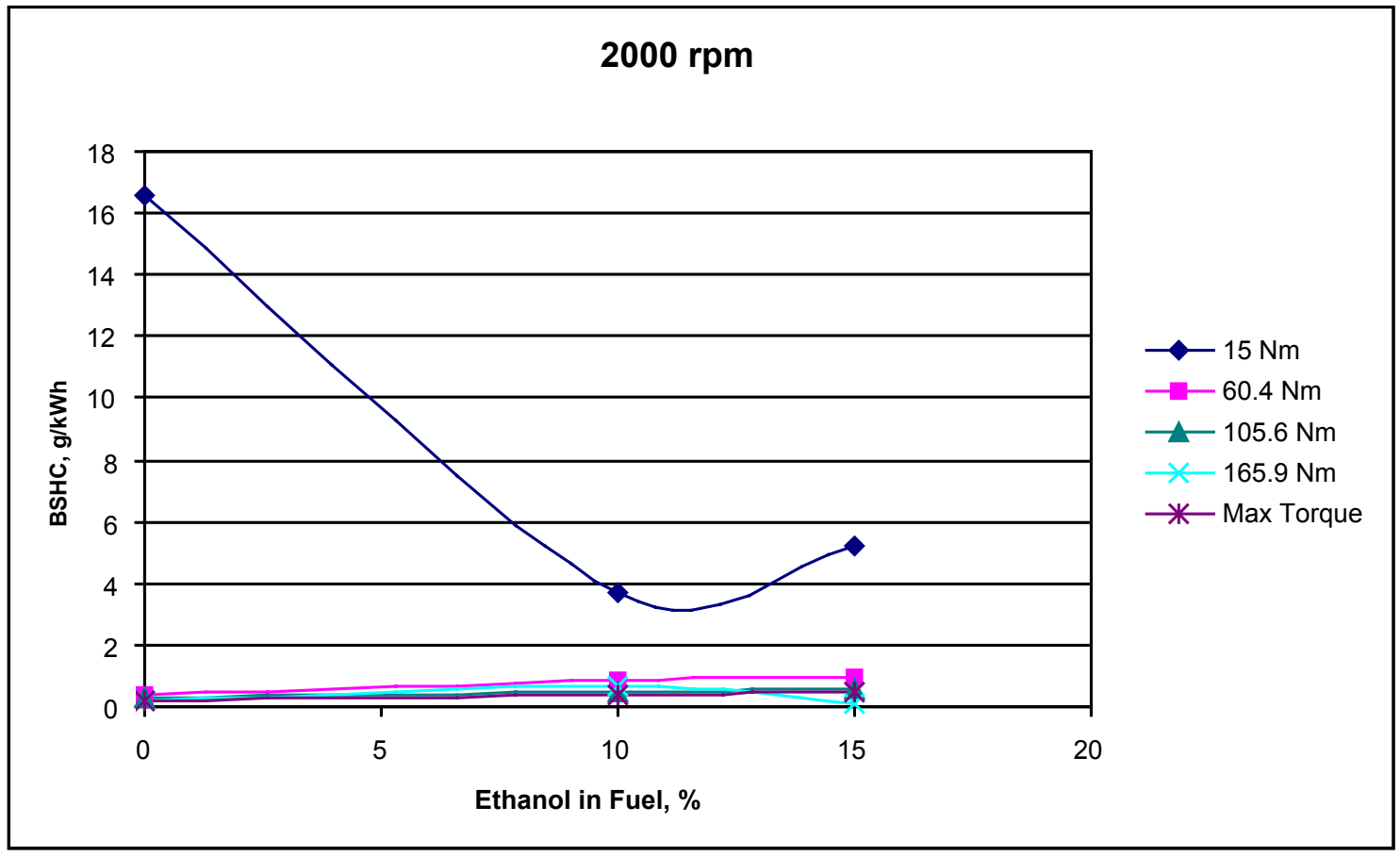

Figure 20 Effect of Ethanol Content of Fuel on BSHC Emissions at 2,000 rpm, with 15-Nm Data

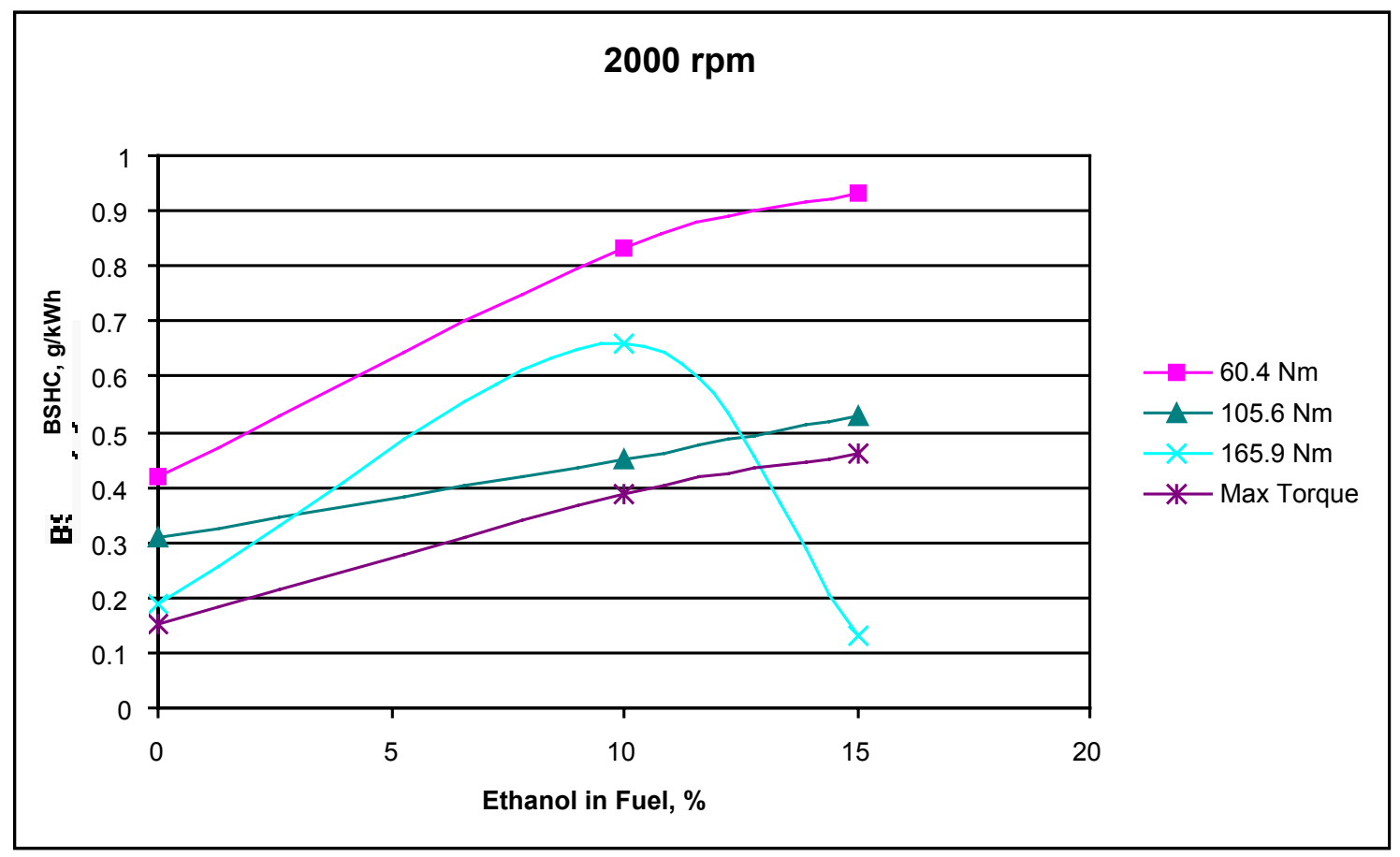

Figure 21 Effect of Ethanol Content of Fuel on BSHC Emissions at 2,000 rpm, without 15-Nm Data 


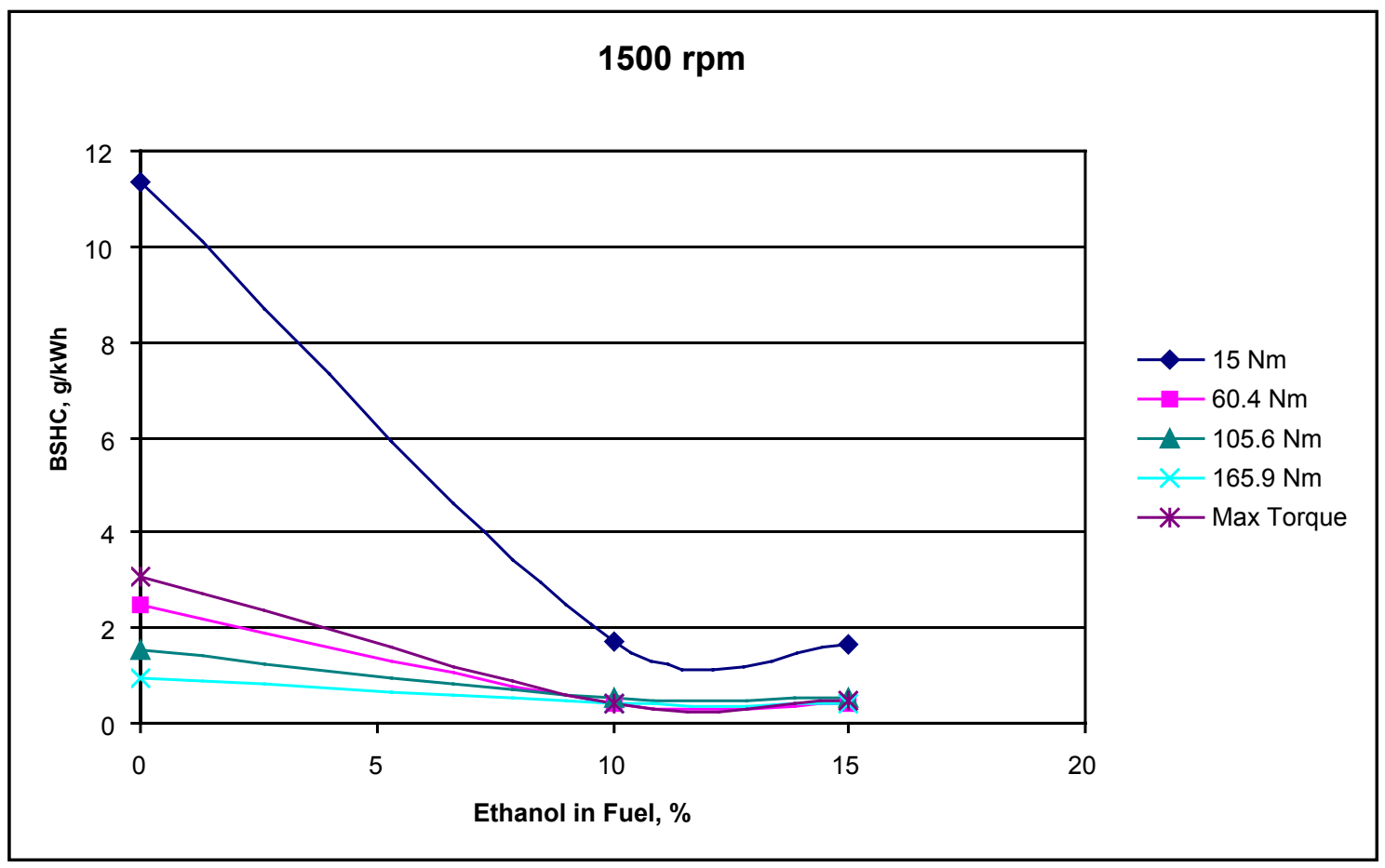

Figure 22 Effect of Ethanol Content of Fuel on BSHC Emissions at 1,500 rpm

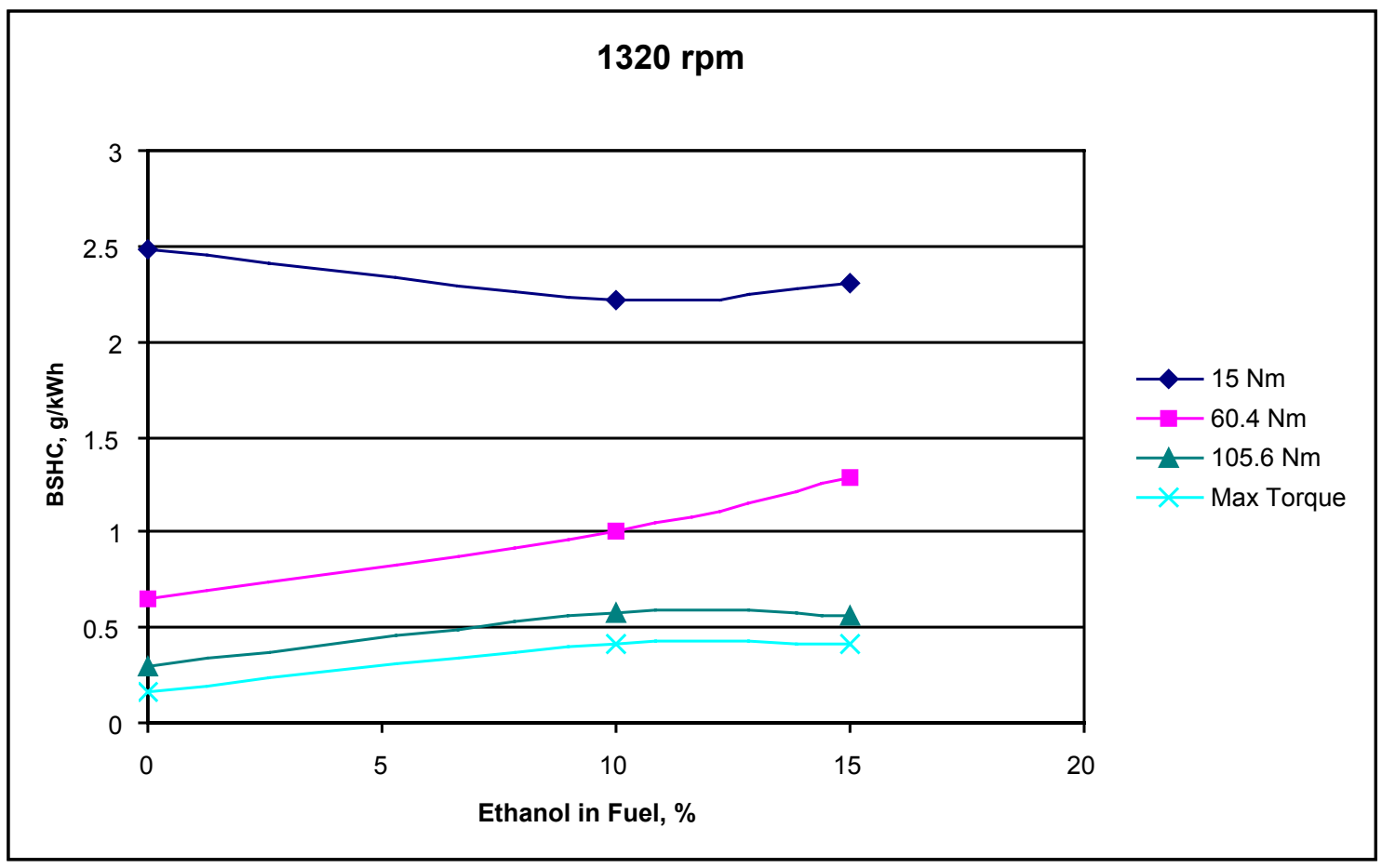

Figure 23 Effect of Ethanol Content of Fuel on BSHC Emissions at 1,320 rpm 


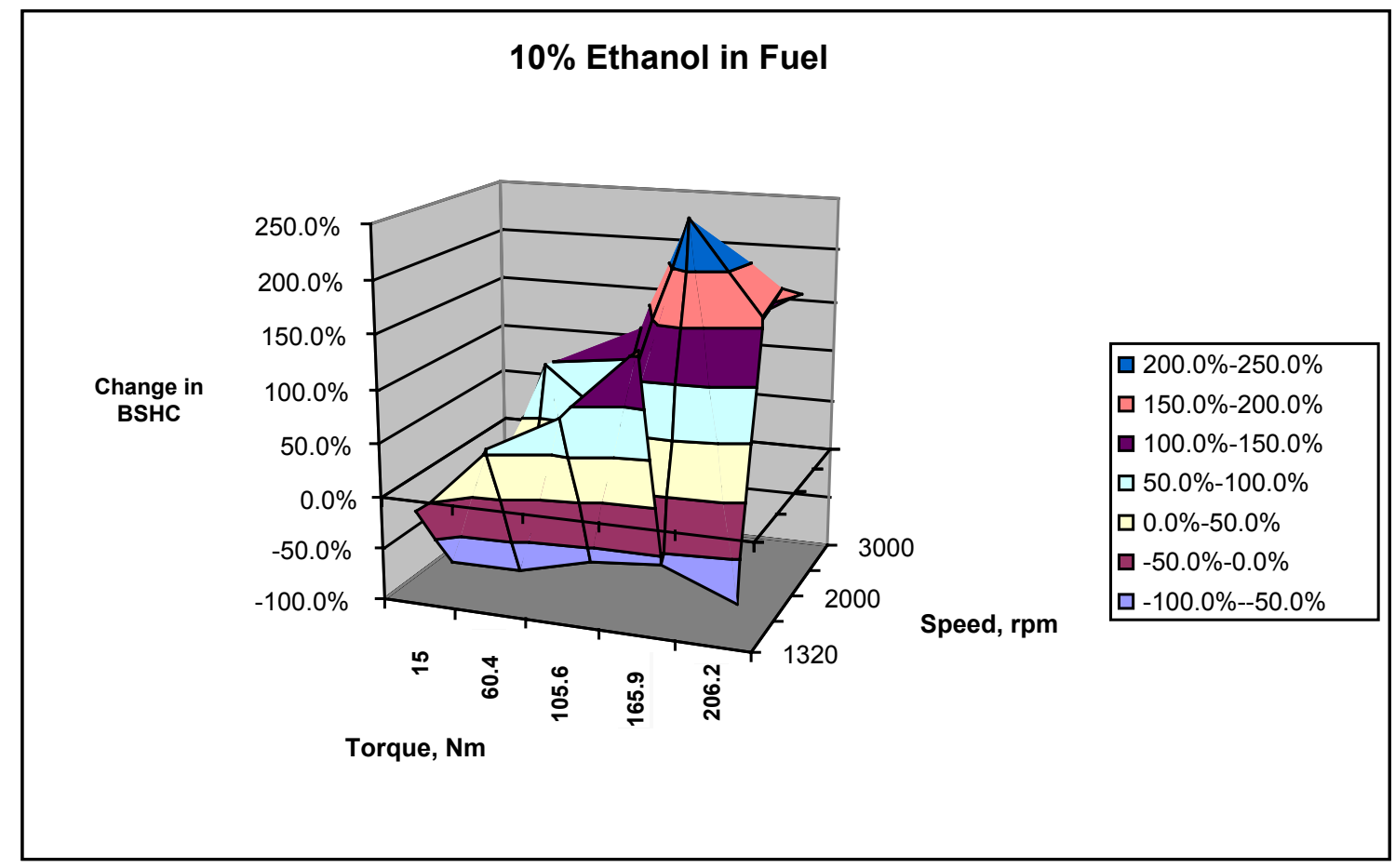

Figure 24 Contour Plot Showing the Effect of 10\% Ethanol on BSHC Emissions

Figure 25 is a top view of Figure 24. Regions where BSHC emissions increase for $10 \%$ ethanol compared to neat diesel fuel are shown in the lighter shades, and regions where BSHC emissions decrease compared to neat diesel fuel are shown in the darker shades. The areas where BSHC decrease make up approximately one-third of the test matrix.

Figure 26 shows a contour plot of the increase in BSHC emissions for the fuel containing $15 \%$ ethanol compared to neat diesel fuel. As occurs in Figure 24, there is a region of decreased $\mathrm{BSHC}$ in a band at 1,500 rpm and in another band along the 15-Nm line. However, the region of decrease along the $15-\mathrm{Nm}$ line does not extend to 3,000 rpm, as it does when $10 \%$ ethanol fuel is used. The points at 2,000 rpm and $165.9 \mathrm{Nm}$ represent a decrease of $32 \%$ instead of a peak increase, as is the case for the $10 \%$-ethanol fuel. The points at 2,000 rpm and $165.9 \mathrm{Nm}$ were identified in the discussion of Figure 21 as being possibly anomalous. Decreases in BSHC emissions along the 1,500-rpm line range from $54 \%$ to $85 \%$ and are similar to the decreases for the $10 \%$ ethanol fuel.

Figure 27 is a top view of Figure 26. Regions where BSHC emissions increase compared to neat diesel fuel are shown in the lighter shades, and regions where BSHC emissions decrease compared to neat diesel fuel are shown in the darker shades. The areas where BSHC emissions decrease make up approximately one-third of the test matrix. 


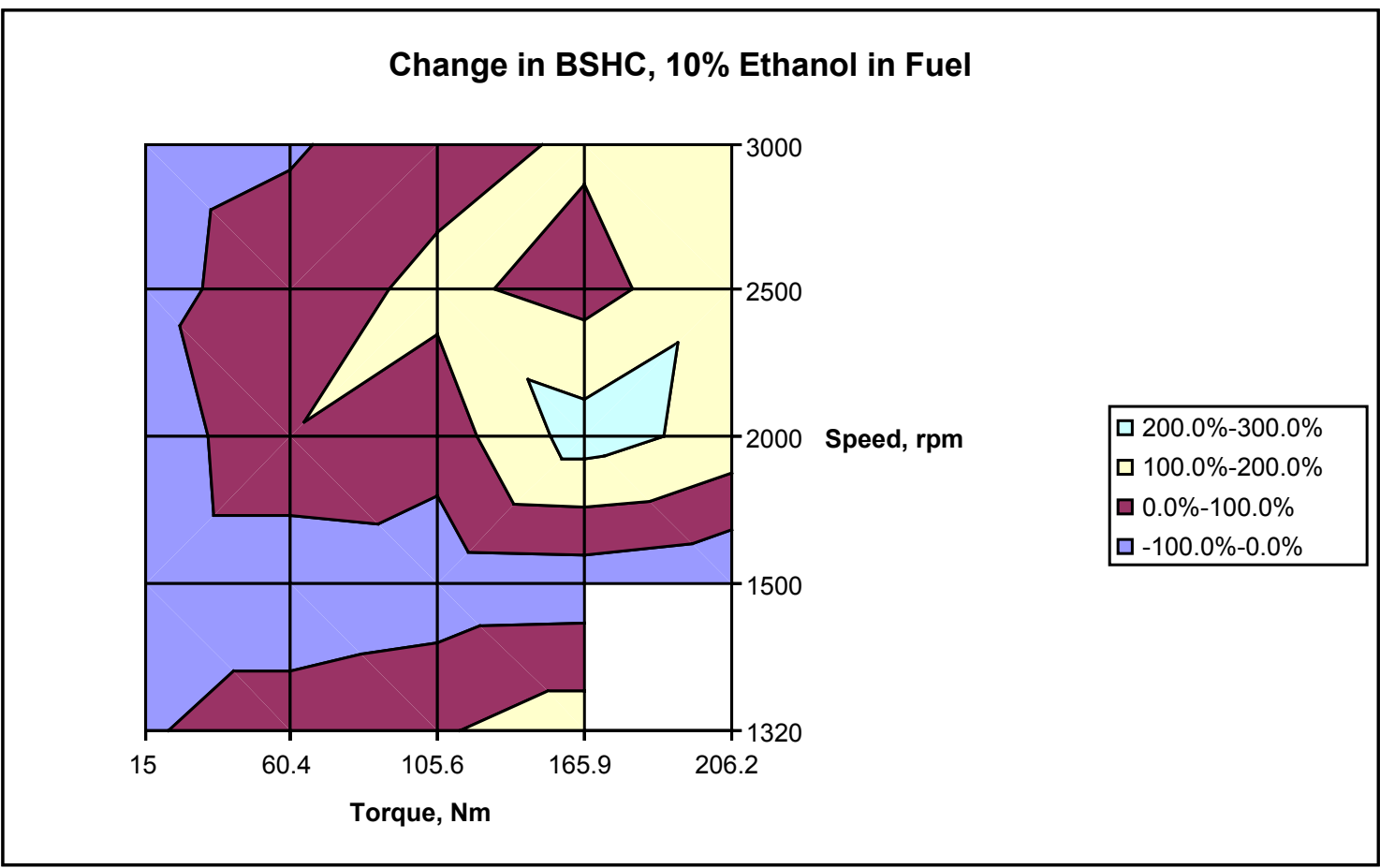

Figure 25 Top View of Figure 24 Showing Regions of Increase (Light) and Decrease (Dark) in BSHC Emissions for Fuel Containing $10 \%$ Ethanol

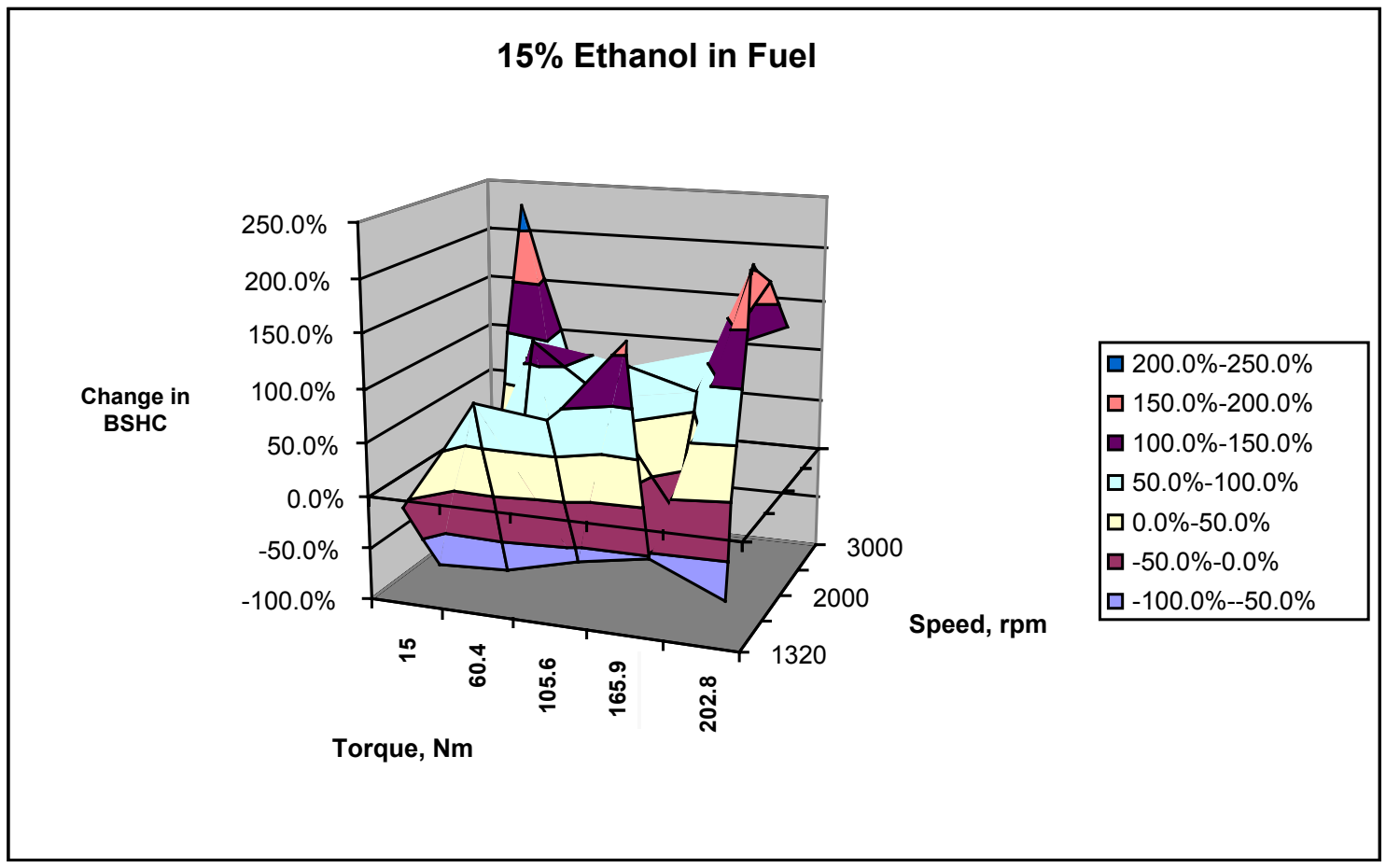

Figure 26 Contour Plot Showing the Effect of 15\% Ethanol on BSHC Emissions 


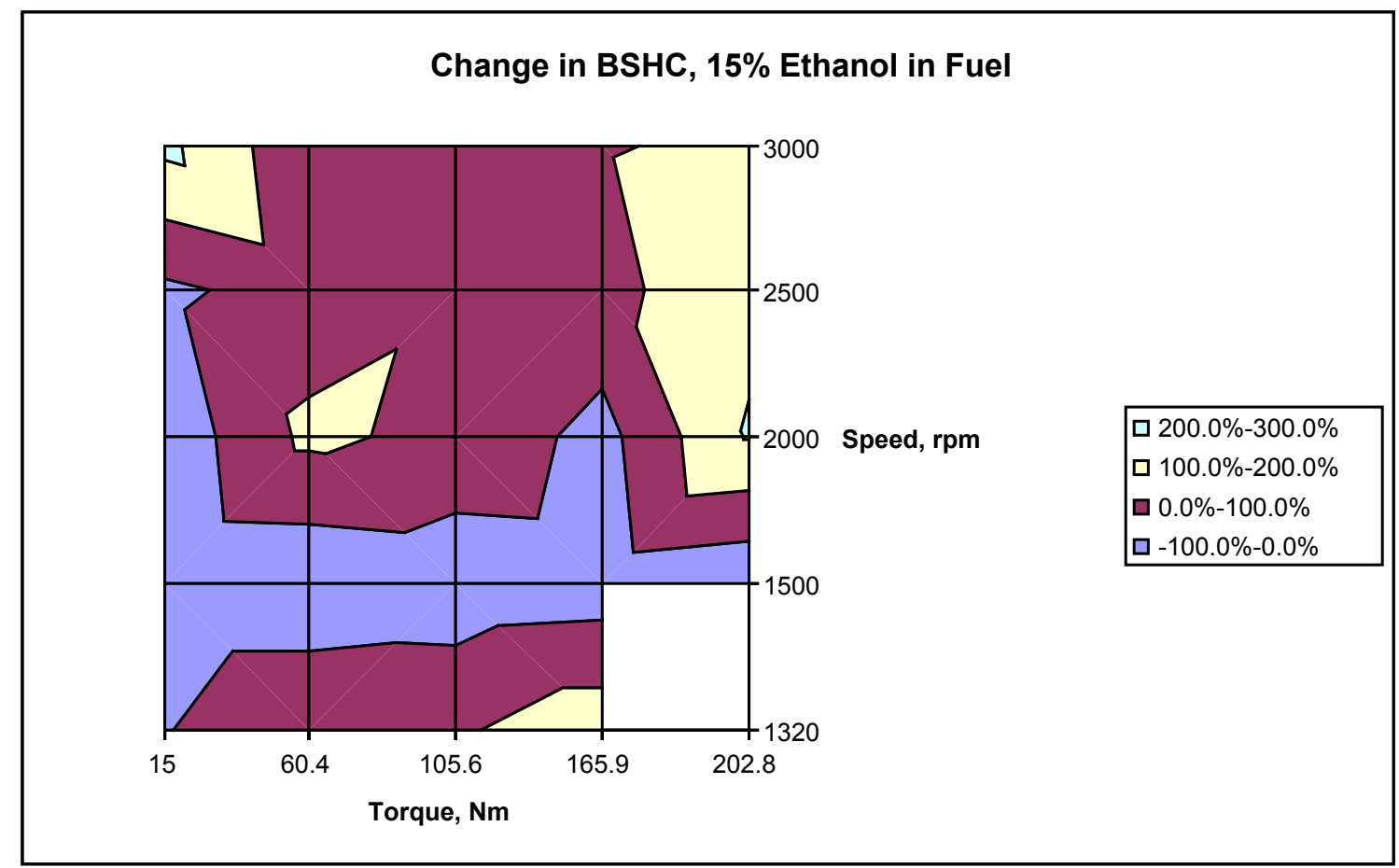

Figure 27 Top View of Figure 26 Showing Regions of Increase (Light) and Decrease (Dark) in BSHC Emissions for Fuel Containing 15\% Ethanol

A comparison of Figure 25 with Figures 9 and 15 and a comparison of Figure 27 with Figures 11 and 17 shows that there are regions where $\mathrm{PM}, \mathrm{NO}_{\mathrm{x}}$, and $\mathrm{HC}$ emissions from $15 \%$ ethanol are reduced simultaneously when compared to these emissions from neat diesel fuel.

\subsection{Carbon Monoxide Emissions on the Test Matrix}

Figure 28 shows the effect of the ethanol content of fuel on brake-specific $\mathrm{CO}$ (BSCO) emissions at 3,000 rpm. The 15-Nm curve is similar to the 15-Nm curves for PM (Figure 2) and $\mathrm{HC}$ (Figure 18); that is, when the $10 \%$ ethanol fuel is used, BSCO emissions are $35 \%$ less than they are when neat diesel fuel is used, but when the $15 \%$ ethanol fuel is used, BSCO emissions are $69 \%$ more than they are when neat diesel fuel is used. Also, the levels of BSCO emissions are far greater at $15 \mathrm{Nm}$ than at other torques, so the 15-Nm curve dominates the scale of the plot.

Figure 29 is the same as Figure 28, except the 15-Nm data have been deleted and the scale of BSCO has been expanded. The 60.4-Nm curve shows that when the $10 \%$ ethanol fuel is used, BSCO emissions are $35 \%$ less than they are when neat diesel fuel is used, and when the $15 \%$ ethanol fuel is used, BSCO emissions are $8 \%$ less they are when neat diesel fuel is used. At higher torques, differences between the ethanol fuels and neat diesel fuel are small. Behaviors at 2,500 and 2,000 rpm are similar to those at 3,000 rpm. 


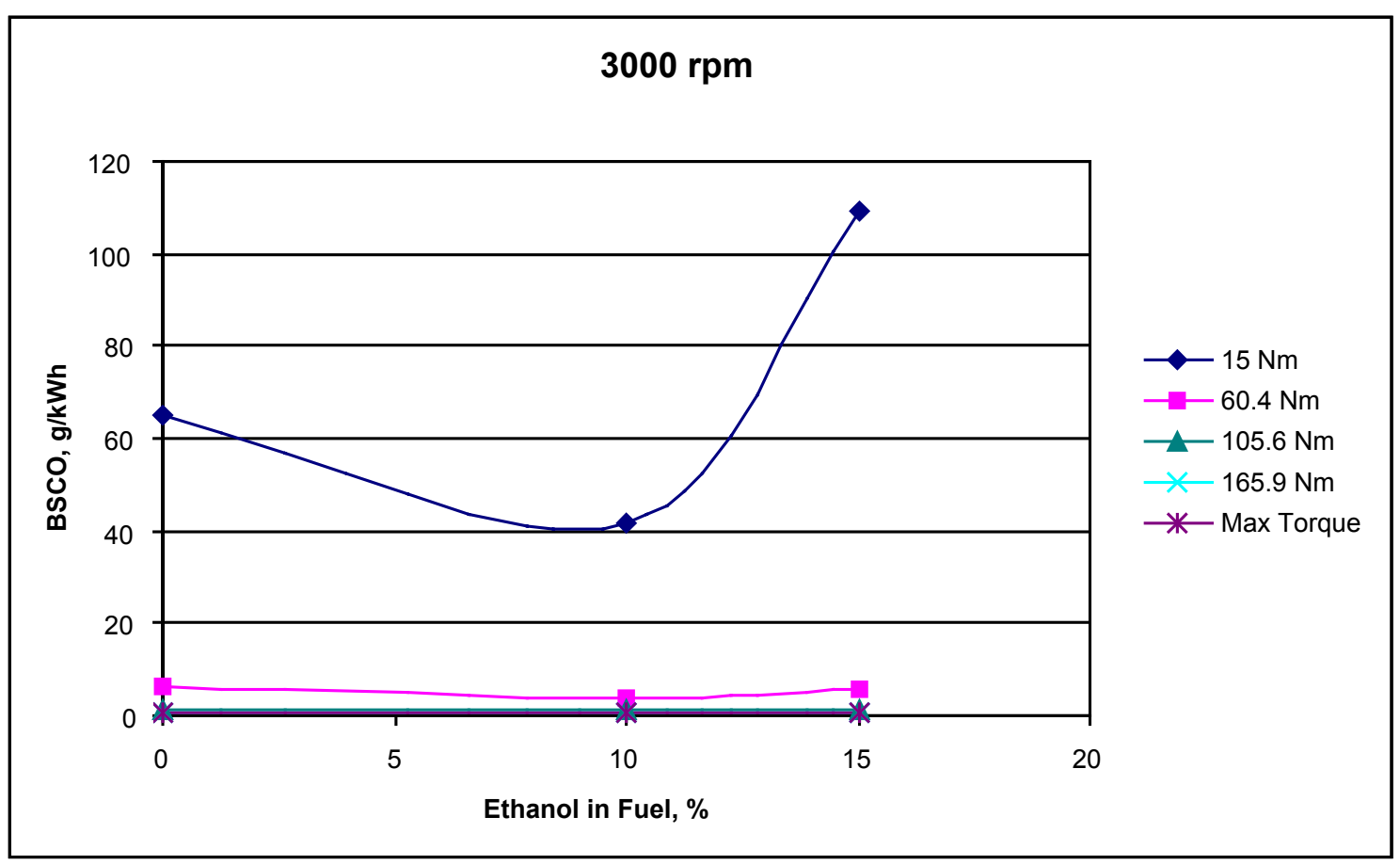

Figure 28 Effect of Ethanol Content of Fuel on BSCO Emissions at 3,000 rpm, with 15-Nm Data

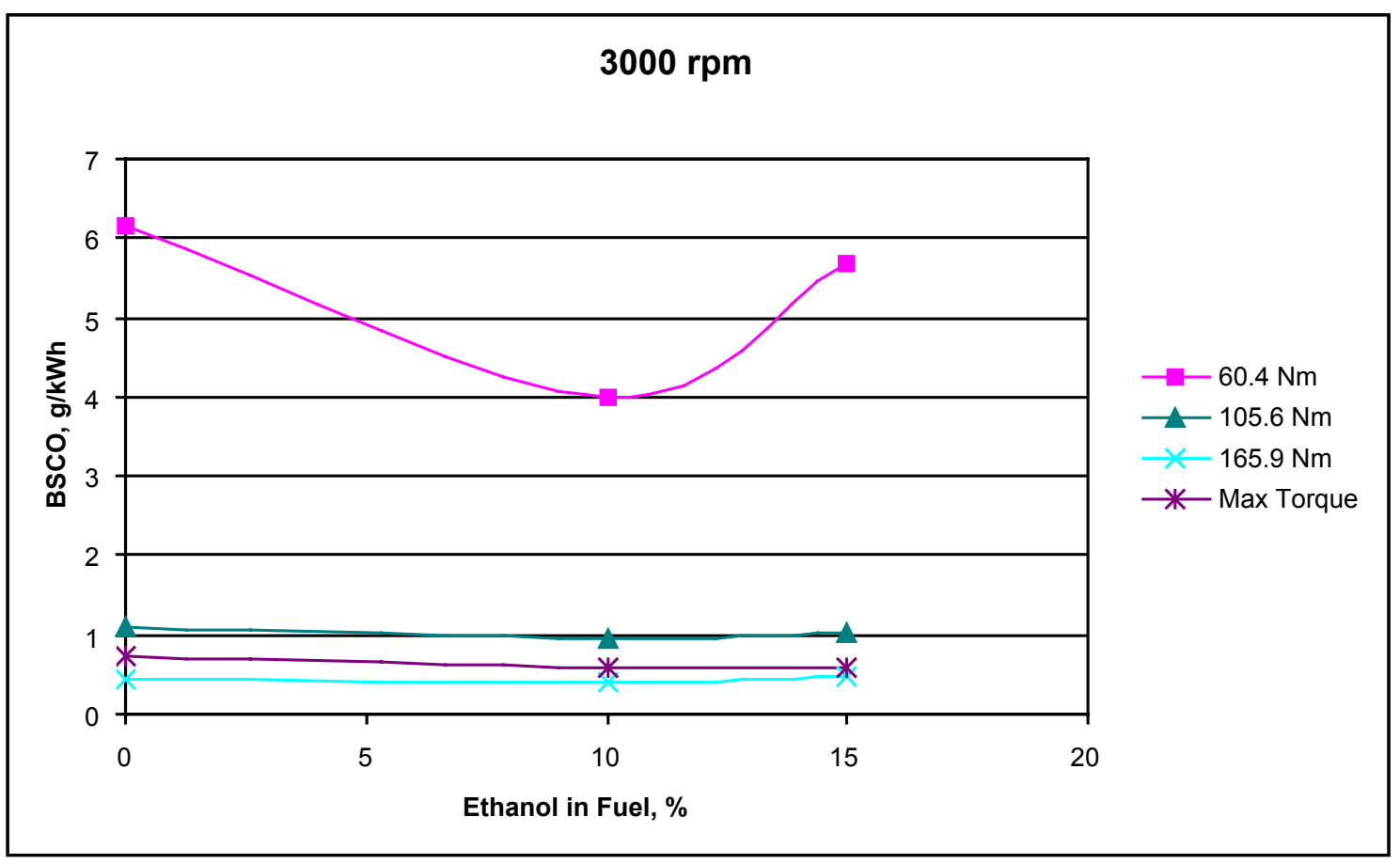

Figure 29 Effect of Ethanol Content of Fuel on BSCO Emissions at 3,000 rpm, without 15-Nm Data 
Figure 30 shows the effect of the ethanol content of fuel on BSCO emissions at 1,500 rpm. The $15-\mathrm{Nm}$ curve shows that when the $10 \%$-ethanol is used, BSCO emissions are $3 \%$ less than they are when neat diesel fuel is used, but when 15\% ethanol fuel is used, BSCO emissions are $24 \%$ more than they are when neat diesel fuel is used. At the maximum torque, adding ethanol to the fuel decreases BSCO emissions by approximately $80 \%$ below those when neat diesel fuel is used. At other torque levels, there is little difference between BSCO emissions when either the ethanol fuels or the neat diesel fuel is used. The trends at $1,320 \mathrm{rpm}$ are similar to the trends at $1,500 \mathrm{rpm}$.

Figure 31 shows a contour plot of the difference in BSCO emissions for the $10 \%$ ethanol fuel compared to neat diesel fuel. Only two points show an increase in BSCO when $10 \%$ ethanol is used instead of neat diesel fuel. They are 1,320 rpm and 1,500 rpm, both at $60.4 \mathrm{Nm}$, where the increases are $20 \%$ and $8 \%$, respectively. At one point, $2,500 \mathrm{rpm}$ at $105.6 \mathrm{Nm}$, there is no change from neat diesel fuel. All of the other points show decreases of up to 76\% in BSCO emissions. The largest decreases occur at low speed and high load.

Figure 32 is a top view of Figure 31. Only the dark region encompassing the points at 1,320 and 1,500 rpm and 60.4 Nm represents an increase in BSCO emissions compared to those when neat diesel fuel is used. The regions where BSCO emissions decrease when $10 \%$ ethanol is used make up approximately $90 \%$ of the test matrix.

Figure 33 shows a contour plot of the difference in BSCO emissions for the $15 \%$ ethanol fuel compared to neat diesel fuel. There is one peak at 3,000 rpm and $15 \mathrm{Nm}$ where BSCO levels increase by $69 \%$ for $15 \%$ ethanol compared to neat diesel fuel, and there is a ridge of increased BSCO emissions from 1,320 rpm and approximately $15 \mathrm{Nm}$ to 3,000 rpm and $105.6 \mathrm{Nm}$. The highest point on the ridge occurs at $1,320 \mathrm{rpm}$ and $60.4 \mathrm{Nm}$, where the increase is $39 \%$. The ridge decreases to a $1 \%$ increase at $2,000 \mathrm{rpm}$ and $105.6 \mathrm{Nm}$, then increases to $9 \%$ increase at $3,000 \mathrm{rpm}$ and $165.9 \mathrm{Nm}$. The largest decrease is $83 \%$ at $1,500 \mathrm{rpm}$ and maximum torque.

Figure 34 is a top view of Figure 33. Regions where BSCO emissions increase for $15 \%$ ethanol compared to neat diesel fuel are shown in the lighter shades, and regions where they decrease are shown in the darker shades. The areas where BSCO emissions decrease make up approximately $60 \%$ of the test matrix.

A comparison of Figure 31 with Figures 9, 15, and 25 and of Figure 33 with Figures 11, 17, and 27 shows that there are regions where $\mathrm{PM}, \mathrm{NO}_{\mathrm{x}}, \mathrm{HC}$, and $\mathrm{CO}$ emissions from $15 \%$ ethanol are reduced simultaneously when compared to these emissions from neat diesel fuel.

\subsection{Emissions at Idle}

Emissions at the 800-rpm idle are shown in Figure 35. Except for the PM emissions that occur when $10 \%$ ethanol is added to the fuel, $\mathrm{NO}_{\mathrm{x}}$ and $\mathrm{PM}$ emissions are $2.4 \%$ to $8.8 \%$ less when ethanol is used than when it is not. These differences are insignificant. 


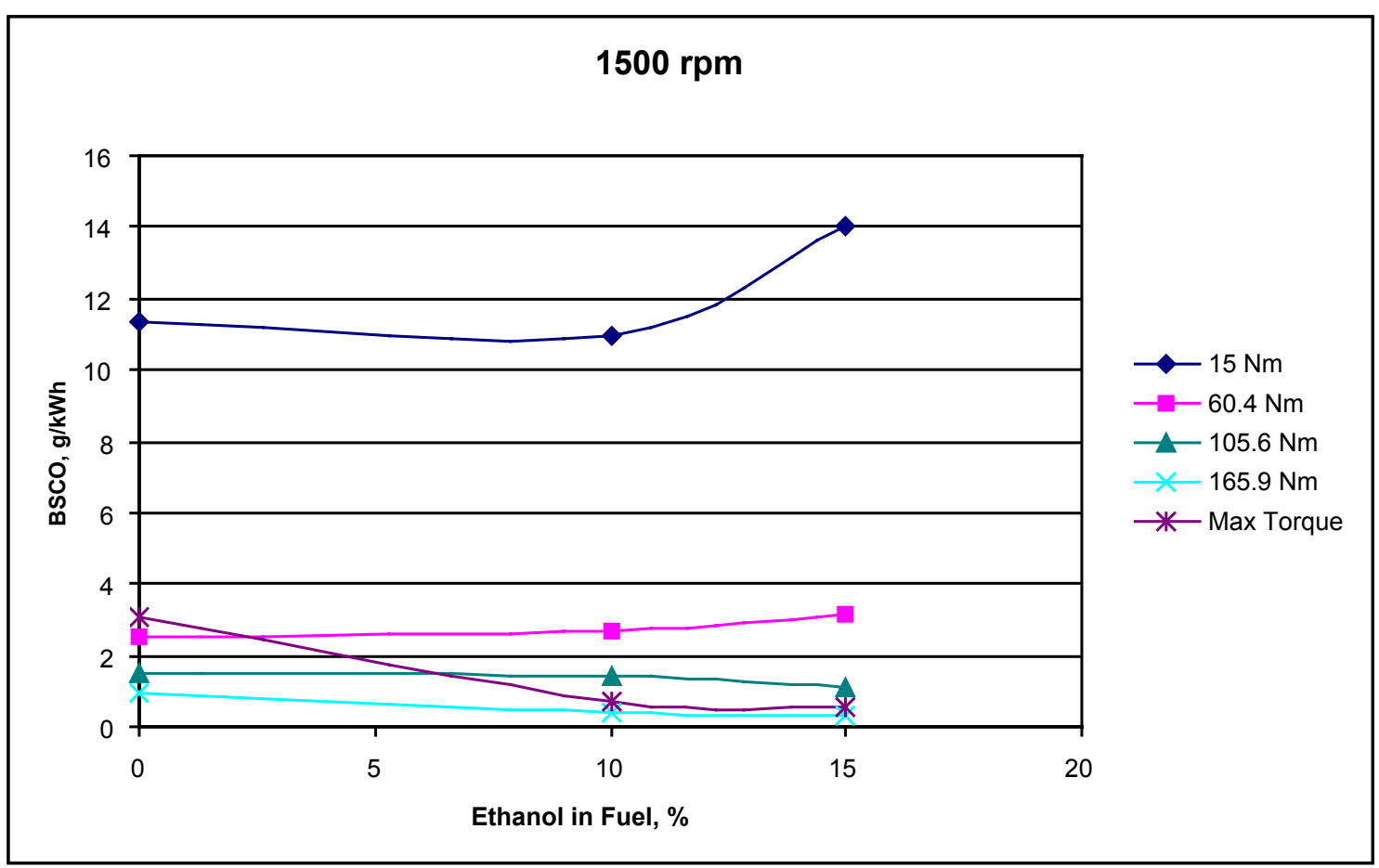

Figure 30 Effect of Ethanol Content of Fuel on BSCO Emissions at 1,500 rpm

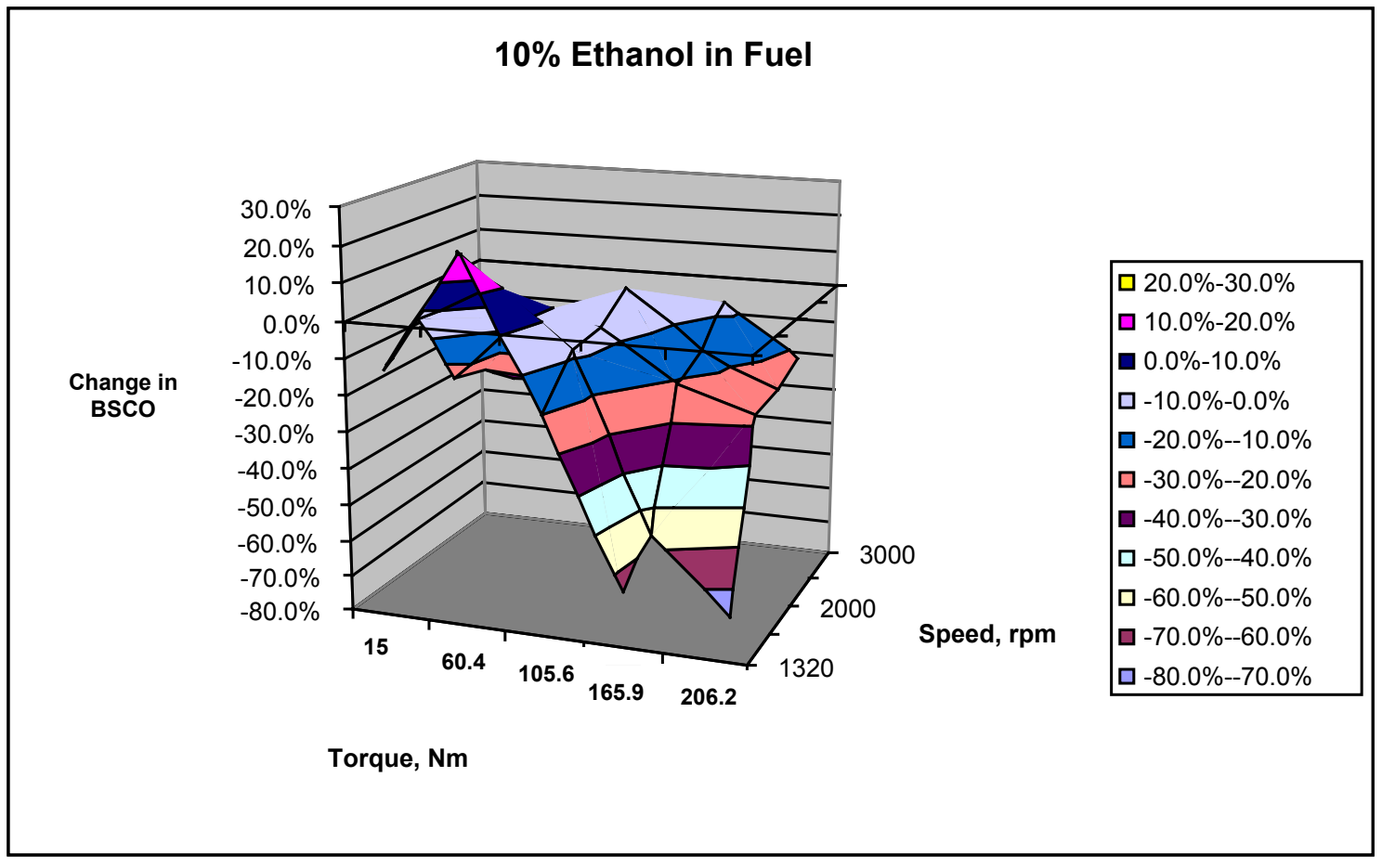

Figure 31 Contour Plot Showing the Effect of $10 \%$ Ethanol on BSCO Emissions 


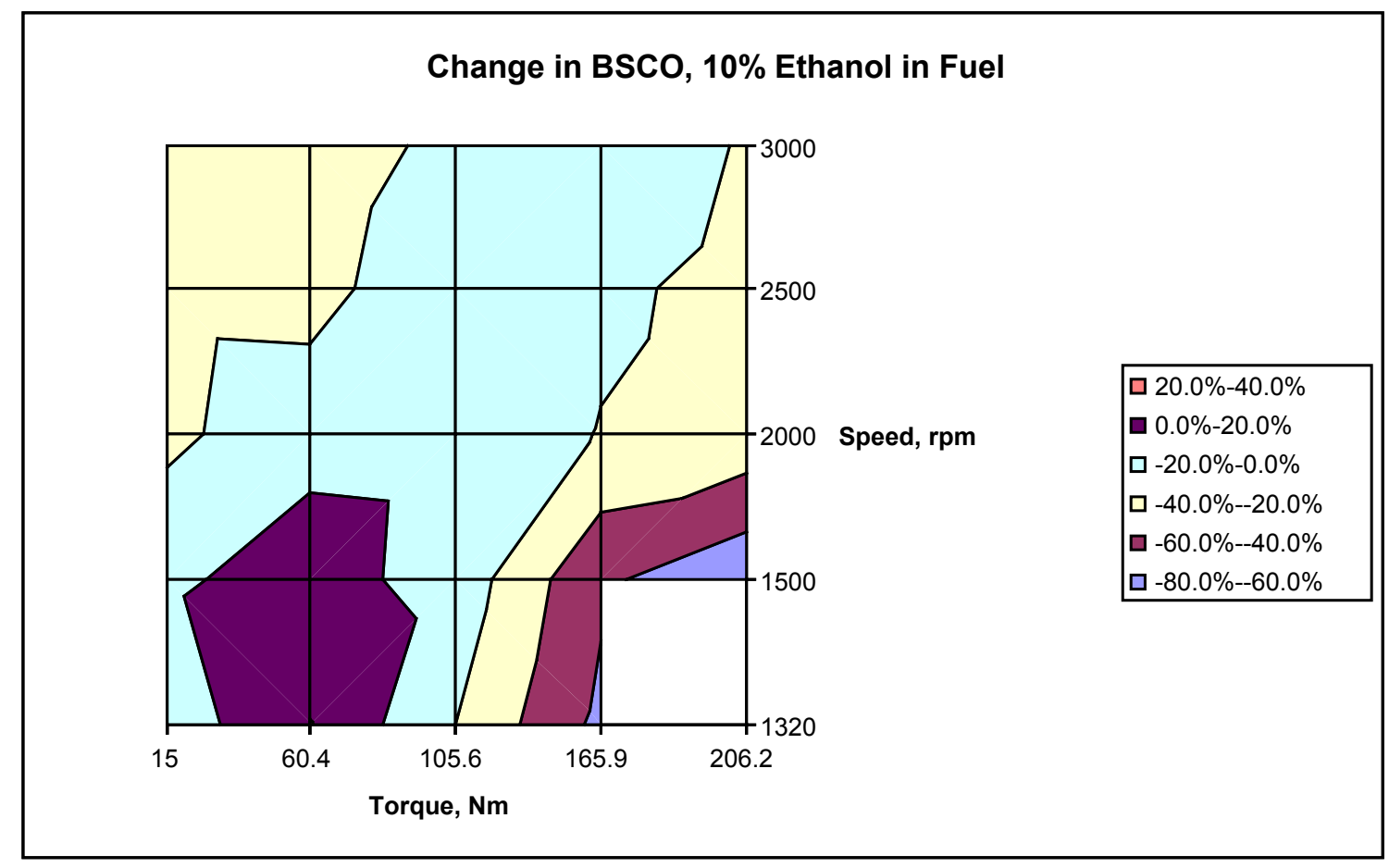

Figure 32 Top View of Figure 31 Showing Regions of Increase and Decrease in BSCO Emissions for Fuel Containing 10\% Ethanol (Only the dark area at 1,320 and 1,500 rpm and $60.4 \mathrm{Nm}$ represents increased BSCO emissions)

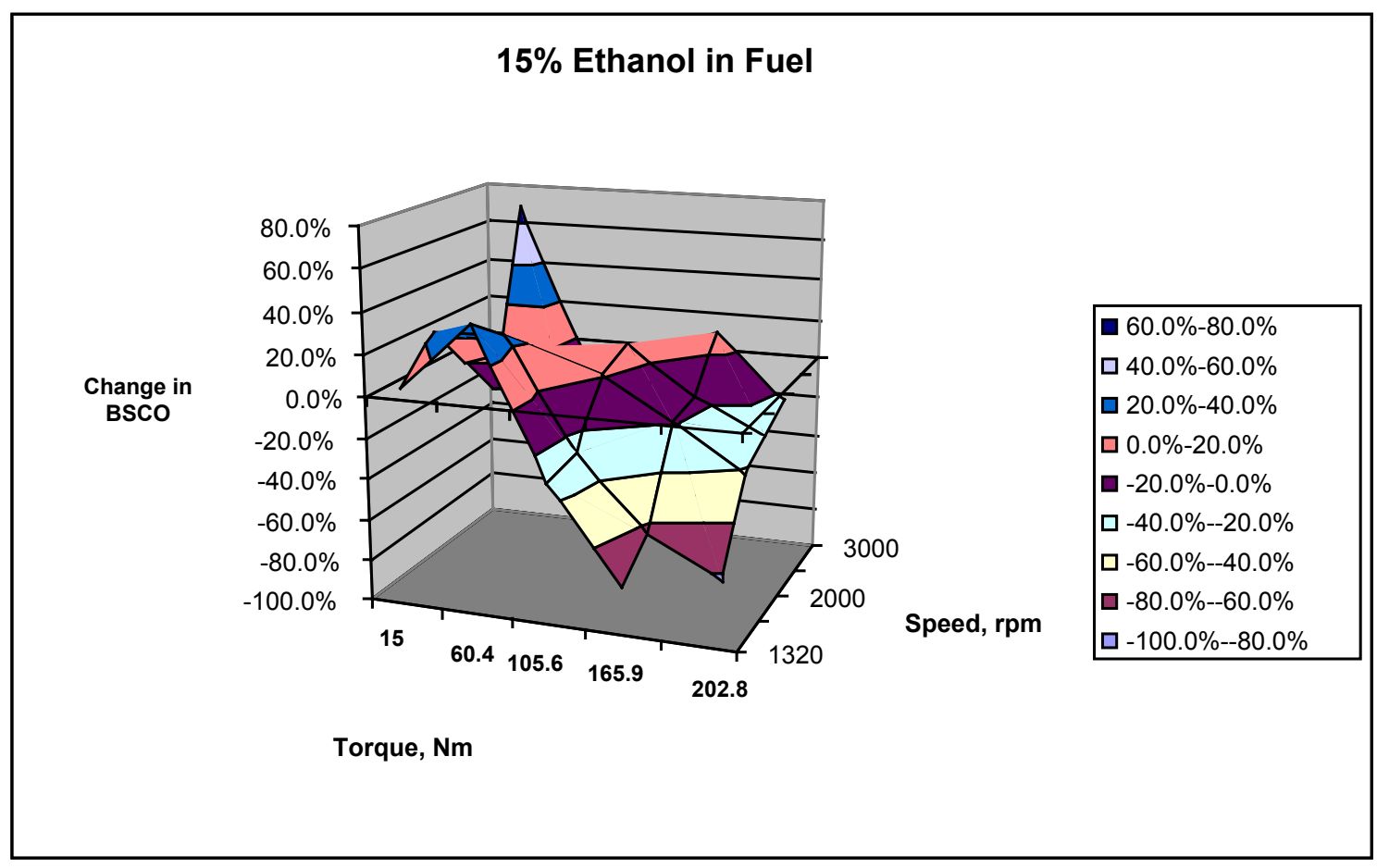

Figure 33 Contour Plot Showing the Effect of 15\% Ethanol on BSCO Emissions 


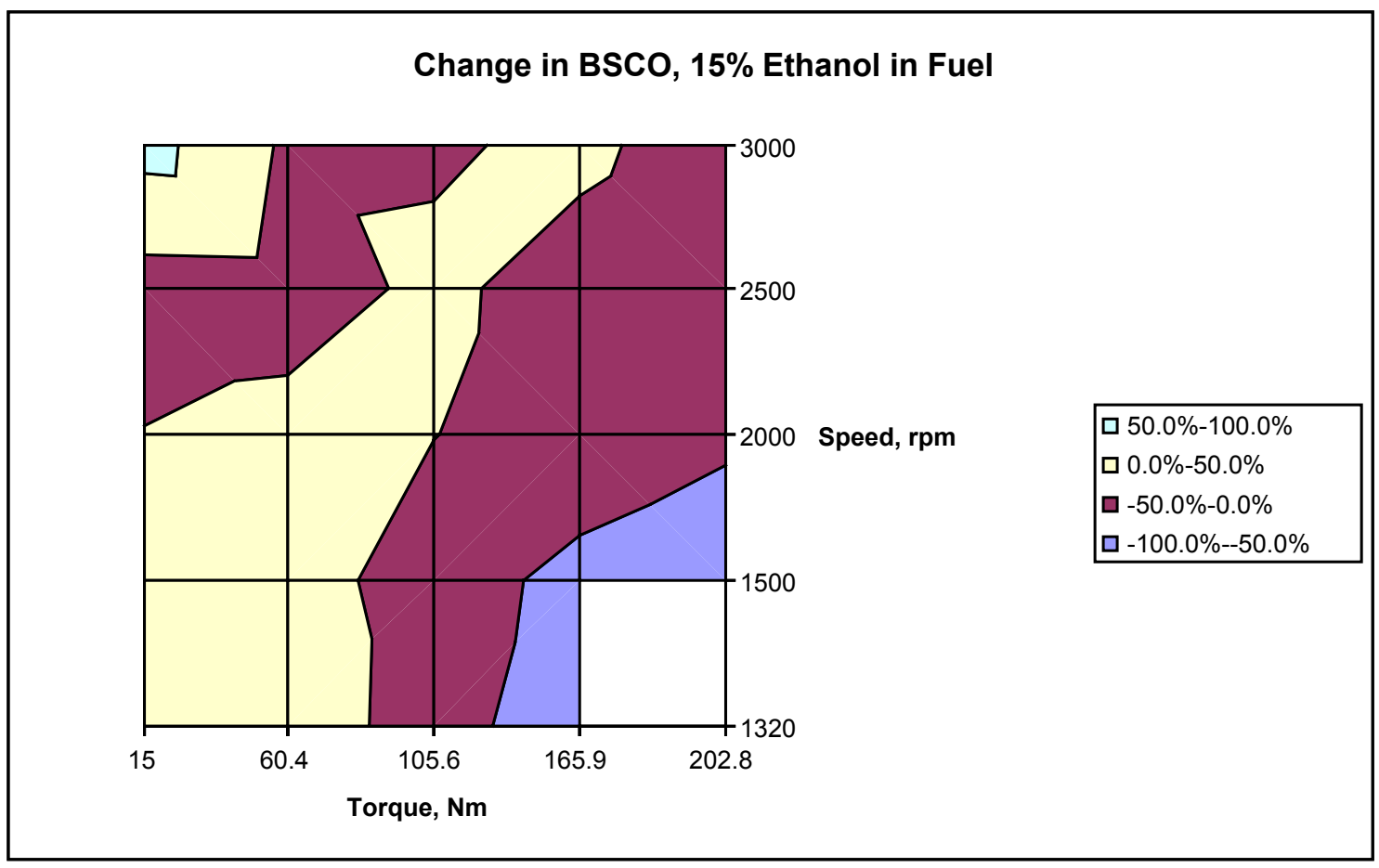

Figure 34 Top View of Figure 33 Showing Regions of Increase (Light) and Decrease (Dark) in BSCO Emissions for Fuel Containing 15\% Ethanol

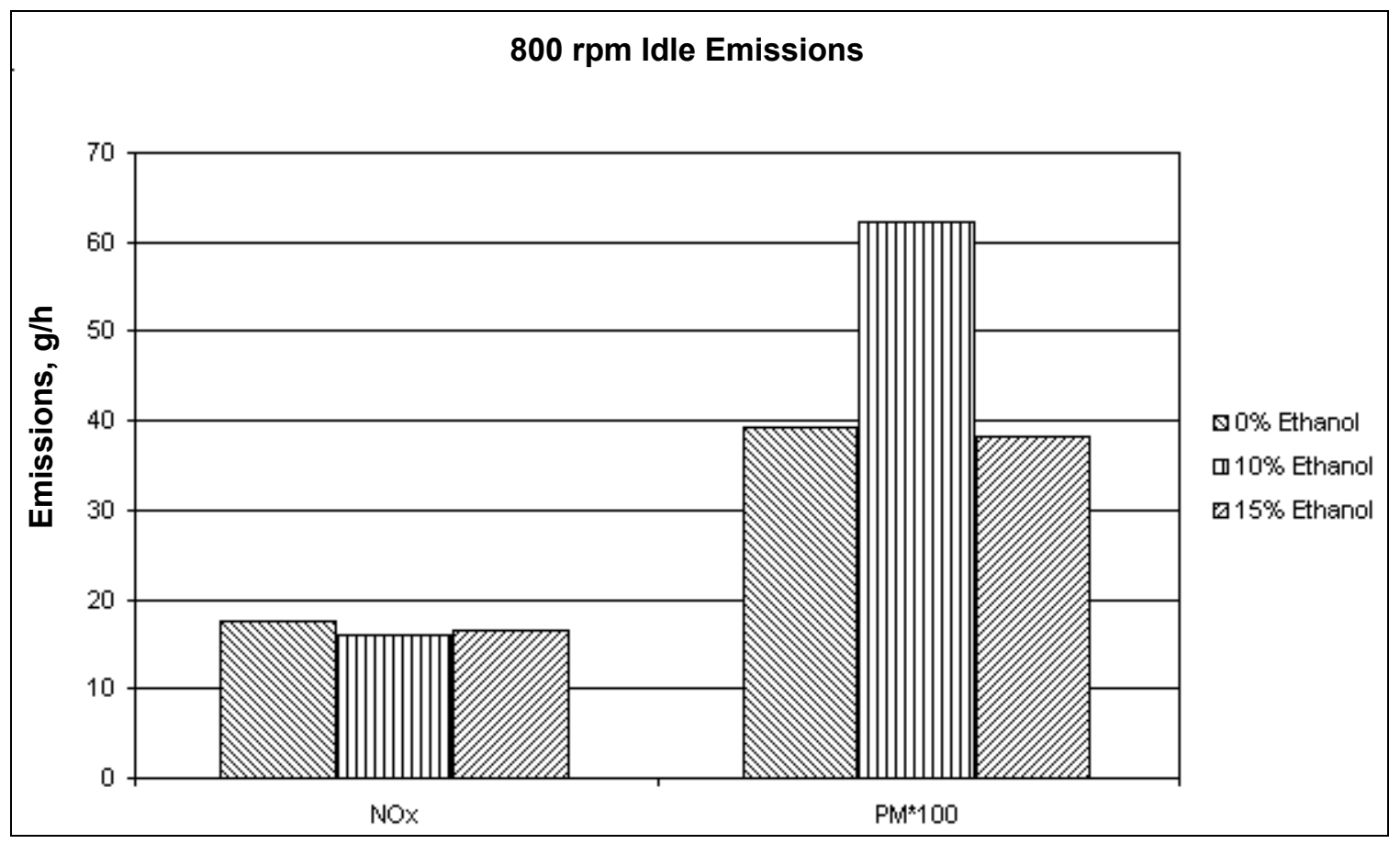

Figure 35 Emissions at 800-rpm Idle 
PM emissions that occur when $10 \%$ ethanol is added to the fuel are $59 \%$ higher than PM emissions when ethanol is not added. This result can be viewed as an experimental error caused by the very low rates of PM production, although no inconsistencies in the measured data were found. The measured data for the nearest similar condition $(1,320 \mathrm{rpm}$ at $15-\mathrm{Nm}$ torque, shown in Figure 7) did not reveal a similar behavior. 
$\Delta$ 


\section{Section 4 Conclusions}

Addition of ethanol to diesel fuel affects both $\mathrm{PM}$ and $\mathrm{NO}_{\mathrm{x}}$ emissions. Addition of $10 \%$ ethanol decreases PM emissions for loads greater than half of maximum torque at all speeds. Addition of $15 \%$ ethanol broadens the region in which PM emissions are decreased to cover approximately two-thirds of the test matrix. This region includes high loads at all speeds and all loads at low speeds; it is the region of greatest interest with regard to heavy-duty engines. PM emissions increase only in the region of high speeds and light loads, which is of little interest with regard to heavy-duty engines. Light-duty engines have a larger variation in operating conditions than do heavy-duty engines, but very light loads at high speeds are rarely encountered. Thus, the same region of decreased PM emissions is also of interest with regard to light-duty engines.

With the addition of $10 \%$ ethanol to the fuel, $\mathrm{NO}_{\mathrm{x}}$ emissions decrease in a narrow range around 1,500 rpm for all loads. With the addition of $15 \%$ ethanol, decreases in $\mathrm{NO}_{\mathrm{x}}$ emissions are concentrated in a roughly rectangular region with loads greater than $105 \mathrm{Nm}$ and speeds less than $1,700 \mathrm{rpm}$. This region is much more limited than the region of decreased PM emissions. Also, with regard to heavy-duty engines, there is a region where $\mathrm{NO}_{\mathrm{x}}$ emissions increase significantly at high loads and speeds of 2,000 to 2,500 rpm.

With most other technologies, a decrease in PM emissions implies an increase in $\mathrm{NO}_{\mathrm{x}}$ emissions. However, when ethanol is added to the fuel, there is an overlap between the region where $\mathrm{PM}$ emissions decrease and the region where $\mathrm{NO}_{\mathrm{x}}$ emissions decrease. With $10 \%$ ethanol in the fuel, the overlap region is the narrow band centered around 1,500 rpm from the $105-\mathrm{Nm}$ (approximately 50\%) load to the maximum load. With 15\% ethanol in the fuel, the overlap region is roughly rectangular with loads greater than $105 \mathrm{Nm}$ (approximately 50\% load) and speeds less than $1,700 \mathrm{rpm}$. In this region, when ethanol is added, PM emissions are reduced by $22-75 \%$ and $\mathrm{NO}_{\mathrm{x}}$ emissions are reduced by $60-84 \%$. These reductions are significant and would be difficult to achieve by any other means. It is likely that a modification of the fuel-injection timing or EGR rate could optimize the regions of $\mathrm{PM}$ and $\mathrm{NO}_{\mathrm{X}}$ reduction, but that is beyond the scope of these tests.

The measurements also show regions of decreased $\mathrm{HC}$ and $\mathrm{CO}$ emissions that overlap with the regions of decreased $\mathrm{PM}$ and $\mathrm{NO}_{\mathrm{x}}$ emissions. The $\mathrm{HC}$ and $\mathrm{CO}$ emissions can be decreased further by using an oxidation catalyst. The unconsumed oxygen in the diesel exhaust provides a favorable condition for the oxidation catalyst.

Measurements at the 800-rpm idle condition revealed small decreases in $\mathrm{PM}$ and $\mathrm{NO}_{\mathrm{x}}$ emissions, except for PM emissions when $10 \%$ ethanol is added to the fuel. This point appears to be inconsistent with other measurements, but there is not enough evidence to either accept or reject it. 
$\Delta$ 


\section{Section 5 \\ Recommendations}

The results indicate that it is possible to find regions where $\mathrm{PM}$ and $\mathrm{NO}_{\mathrm{x}}$ emissions are reduced by the addition of ethanol to the fuel. In addition, it may be possible to find regions in which both $\mathrm{PM}$ and $\mathrm{NO}_{\mathrm{x}}$ emissions are reduced simultaneously. These results were obtained by taking measurements from a light-duty engine having a particular design and should not be extrapolated directly to heavy-duty engines. Confirmation of these possibilities requires testing on a heavy-duty engine.

These tests were performed on an engine that has EGR. Similar tests on an engine that does not have EGR would determine whether $\mathrm{PM}$ and $\mathrm{NO}_{\mathrm{x}}$ emissions can be reduced for such an engine.

The engine was tested only with its standard injection timing and EGR rate. The injection timing and EGR rate are known to affect both $\mathrm{PM}$ and $\mathrm{NO}_{\mathrm{x}}$ emissions. Additional tests could determine whether a modified injection timing and EGR rate would enhance the effects of ethanol.

Finally, the nonlinearities in the trends could be investigated to determine whether they could be exploited. 
$\Delta$ 


\section{Section 6 \\ References}

Ahmed, I., and N.J. Marek, 1999, “The OxyDiesel Project: An Ethanol-Based Diesel

Alternative," paper presented at the National Conference on Ethanol Policy and Marketing, Las Vegas, Nev., Feb. 22-24.

Bechtold, R.L., et al., 1991, "Performance and Emissions of a DDC 8V-71 Transit Bus Engine Using Ignition-Improved Methanol and Ethanol," SAE Paper 912356, Society of Automotive Engineers, Warrendale, Penn.

Moses, C.A., et al., 1980, "Experiments with Alcohol/Diesel Fuel Blends in CompressionIgnition Engines," in Proceedings of the Fourth International Symposium on Alcohol Fuels Technology, Brazil.

Shih, L.K.-L., 1998, "Comparison of the Effects of Various Fuel Additives on Diesel Emissions," SAE Paper 982573, Society of Automotive Engineers, Warrendale, Penn.

Society of Automotive Engineers, 1995, Diesel Engine Emission Measurement Procedure, Standard J1003, Warrenville, Penn., June.

Toepel, R.R., et al., 1983, "Development of Detroit Diesel Allison 6V-92TA Methanol Fueled Coach Engine," SAE Paper 831744, Society of Automotive Engineers, Warrendale, Penn. 
$\Delta$ 


\section{Fuel Consumption and Emissions Data}

Table A.1 Fuel Consumption Data

\begin{tabular}{|c|c|c|c|c|c|}
\hline $\begin{array}{c}\text { Torque } \\
\text { (Nm) }\end{array}$ & $\begin{array}{c}\text { Ethanol } \\
(\%)\end{array}$ & $\begin{array}{c}\text { Fuel } \\
\text { (g/min) }\end{array}$ & $\begin{array}{c}\text { Torque } \\
\text { (Nm) }\end{array}$ & $\begin{array}{c}\text { Ethanol } \\
(\%)\end{array}$ & $\begin{array}{c}\text { Fuel } \\
\text { (g/min) }\end{array}$ \\
\hline $3,000 \mathrm{rpm}$ & & & $1,500 \mathrm{rpm}$ & & \\
\hline 15 & 0 & 72.3 & 15 & 0 & 25.9 \\
\hline 15 & 10 & 56.8 & 15 & 10 & 26.3 \\
\hline 15 & 15 & 69 & 15 & 15 & 27.2 \\
\hline 60.3 & 0 & 94.9 & 60.4 & 0 & 46.9 \\
\hline 60.4 & 10 & 99.1 & 60.4 & 10 & 48.6 \\
\hline 60.4 & 15 & 98.3 & 60.4 & 15 & 49.2 \\
\hline 105.6 & 0 & 138.2 & 105.6 & 0 & 69.7 \\
\hline 105.6 & 10 & 144.3 & 105.6 & 10 & 72.8 \\
\hline 105.6 & 15 & 144 & 105.6 & 15 & 73.1 \\
\hline 165.7 & 0 & 188.3 & 165.9 & 0 & 98.2 \\
\hline 165.9 & 10 & 198.1 & 165.9 & 10 & 100.6 \\
\hline 165.9 & 15 & 201.4 & 165.9 & 15 & 103.7 \\
\hline 224.1 & 0 & 254.9 & 218.1 & 0 & 129.25 \\
\hline 206.2 & 10 & 247.7 & 201.6 & 10 & 121.3 \\
\hline 202.8 & 15. & 243.4 & 196.9 & 15 & 120.8 \\
\hline $2,500 \mathrm{rpm}$ & & & $1,320 \mathrm{rpm}$ & & \\
\hline 14.9 & 0 & 55.7 & 15 & 0 & 23.2 \\
\hline 15 & 10 & 49.2 & 15 & 10 & 25.7 \\
\hline 15 & 15 & 53.8 & 15 & 15 & 24 \\
\hline 60.4 & 0 & 76.7 & 60.4 & 0 & 43.3 \\
\hline 60.4 & 10 & 78.2 & 60.4 & 10 & 45.8 \\
\hline 60.4 & 15 & 78.4 & 60.4 & 15 & 43.1 \\
\hline 105.6 & 0 & 109.6 & 105.6 & 0 & 62 \\
\hline 105.6 & 10 & 119.8 & 105.6 & 10 & 63.9 \\
\hline 105.6 & 15 & 116.9 & 105.6 & 15 & 64 \\
\hline 165.9 & 0 & 162.7 & 201.8 & 0 & 112 \\
\hline 165.9 & 10 & 166.6 & 189.5 & 10 & 107.2 \\
\hline 165.9 & 15 & 168 & 177.5 & 15 & 101.1 \\
\hline 236 & 0 & 224.9 & & & \\
\hline 216.7 & 10 & 215.7 & & & \\
\hline 216 & 15 & 214.5 & & & \\
\hline \multicolumn{6}{|l|}{$2,000 \mathrm{rpm}$} \\
\hline 15 & 0 & 35.7 & & & \\
\hline 15 & 10 & 34 & & & \\
\hline 15 & 15 & 35 & & & \\
\hline 60.4 & 0 & 60.2 & & & \\
\hline 60.4 & 10 & 61.9 & & & \\
\hline 60.4 & 15 & 62.5 & & & \\
\hline 105.6 & 0 & 92.4 & & & \\
\hline 105.6 & 10 & 94.9 & & & \\
\hline 105.6 & 15 & 94.8 & & & \\
\hline 166 & 0 & 130.7 & & & \\
\hline 165.9 & 10 & 134.6 & & & \\
\hline 165.9 & 15 & 133.9 & & & \\
\hline 239.9 & 0 & 182.3 & & & \\
\hline 220.6 & 10 & 175.3 & & & \\
\hline 220.5 & 15 & 173.9 & & & \\
\hline
\end{tabular}


Table A.2 Particulate Matter Emissions Data

\begin{tabular}{|c|c|c|c|c|c|c|c|}
\hline $\begin{array}{c}\text { Torque } \\
\text { (Nm) }\end{array}$ & $\begin{array}{c}\text { Ethanol } \\
(\%)\end{array}$ & $\begin{array}{c}\text { BSPM } \\
\text { (g/kWh) }\end{array}$ & $\begin{array}{c}\text { Change } \\
(\%)\end{array}$ & $\begin{array}{c}\text { Torque } \\
\text { (Nm) }\end{array}$ & $\begin{array}{c}\text { Ethanol } \\
(\%)\end{array}$ & $\begin{array}{c}\text { BSPM } \\
\text { (g/kWh) }\end{array}$ & $\begin{array}{c}\text { Change } \\
(\%)\end{array}$ \\
\hline $3,000 \mathrm{rpm}$ & & & & $1,500 \mathrm{rpm}$ & & & \\
\hline 15 & 0 & 5.7979 & & 15 & 0 & 0.5405 & \\
\hline 15 & 10 & 1.5438 & -73.4 & 15 & 10 & 0.6505 & 20.4 \\
\hline 15 & 15 & 6.8155 & 17.6 & 15 & 15 & 0.5691 & 5.3 \\
\hline 60.3 & 0 & 0.1716 & & 60.4 & 0 & 0.2939 & \\
\hline 60.4 & 10 & 0.2769 & 61.4 & 60.4 & 10 & 0.3556 & 21.0 \\
\hline 60.4 & 15 & 0.2742 & 59.8 & 60.4 & 15 & 0.2777 & -5.5 \\
\hline 105.6 & 0 & 0.19 & & 105.6 & 0 & 0.3708 & \\
\hline 105.6 & 10 & 0.209 & 10.0 & 105.6 & 10 & 0.3724 & 0.4 \\
\hline 105.6 & 15 & 0.2023 & 6.5 & 105.6 & 15 & 0.2348 & -36.7 \\
\hline 165.7 & 0 & 0.1361 & & 165.9 & 0 & 0.1516 & \\
\hline 165.9 & 10 & 0.157 & 15.4 & 165.9 & 10 & 0.1134 & -25.2 \\
\hline 165.9 & 15 & 0.1579 & 16.0 & 165.9 & 15 & 0.1171 & -22.8 \\
\hline 224.1 & 0 & 0.2127 & & 218.1 & 0 & 0.2716 & \\
\hline 206.2 & 10 & 0.1529 & -28.1 & 201.6 & 10 & 0.0952 & -64.9 \\
\hline 2028 & 15. & 0.1506 & -29.2 & 196.9 & 15 & 0.0964 & -64.5 \\
\hline $2,500 \mathrm{rpm}$ & & & & $1,320 \mathrm{rpm}$ & & & \\
\hline 14.9 & 0 & 4.7166 & & 15 & 0 & 0.8636 & \\
\hline 15 & 10 & 4.4776 & -5.1 & 15 & 10 & 0.894 & 3.5 \\
\hline 15 & 15 & 4.5856 & -2.8 & 15 & 15 & 0.6659 & -22.9 \\
\hline 60.4 & 0 & 0.1588 & & 60.4 & 0 & 0.3741 & \\
\hline 60.4 & 10 & 0.2377 & 49.7 & 60.4 & 10 & 0.4202 & 12.3 \\
\hline 60.4 & 15 & 0.2053 & 29.3 & 60.4 & 15 & 0.2278 & -39.1 \\
\hline 105.6 & 0 & 0.1669 & & 105.6 & 0 & 0.3466 & \\
\hline 105.6 & 10 & 0.1801 & 7.9 & 105.6 & 10 & 0.2285 & -34.1 \\
\hline 105.6 & 15 & 0.1665 & -0.2 & 105.6 & 15 & 0.1891 & -45.4 \\
\hline 165.9 & 0 & 0.165 & & 201.8 & 0 & 0.4758 & \\
\hline 165.9 & 10 & 0.1495 & -9.4 & 189.5 & 10 & 0.1612 & -66.1 \\
\hline 165.9 & 15 & 0.1423 & -13.8 & 177.5 & 15 & 0.1203 & -74.7 \\
\hline 236 & 0 & 0.2124 & & & & & \\
\hline 216.7 & 10 & 0.1495 & -29.6 & & & & \\
\hline 216 & 15 & 0.1247 & -41.3 & & & & \\
\hline \multicolumn{8}{|l|}{$2,000 \mathrm{rpm}$} \\
\hline 15 & 0 & 1.2171 & & & & & \\
\hline 15 & 10 & 0.9049 & -25.7 & & & & \\
\hline 15 & 15 & 1.3129 & 7.9 & & & & \\
\hline 60.4 & 0 & 0.3011 & & & & & \\
\hline 60.4 & 10 & 0.2564 & -14.8 & & & & \\
\hline 60.4 & 15 & 0.2267 & -24.7 & & & & \\
\hline 105.6 & 0 & 0.1863 & & & & & \\
\hline 105.6 & 10 & 0.1927 & 3.4 & & & & \\
\hline 105.6 & 15 & 0.1597 & -14.3 & & & & \\
\hline 166 & 0 & 0.167 & & & & & \\
\hline 165.9 & 10 & 0.1396 & -16.4 & & & & \\
\hline 165.9 & 15 & 0.1243 & -25.6 & & & & \\
\hline 239.9 & 0 & 0.1657 & & & & & \\
\hline 220.6 & 10 & 0.1111 & -33.0 & & & & \\
\hline 220.5 & 15 & 0.0897 & -45.9 & & & & \\
\hline
\end{tabular}


Table A.3 Nitrogen Oxides Emissions Data

\begin{tabular}{|c|c|c|c|c|c|c|c|}
\hline $\begin{array}{c}\text { Torque } \\
\text { (Nm) }\end{array}$ & $\begin{array}{c}\text { Ethanol } \\
(\%)\end{array}$ & $\begin{array}{l}\text { BSNO }_{x} \\
\text { (g/kWh) }\end{array}$ & $\begin{array}{c}\text { Change } \\
(\%)\end{array}$ & $\begin{array}{c}\text { Torque } \\
\text { (Nm) }\end{array}$ & $\begin{array}{c}\text { Ethanol } \\
(\%)\end{array}$ & $\begin{array}{l}\text { BSNO }_{x} \\
\text { (g/kWh) }\end{array}$ & $\begin{array}{c}\text { Change } \\
(\%)\end{array}$ \\
\hline $3,000 \mathrm{rpm}$ & & & & $1,500 \mathrm{rpm}$ & & & \\
\hline 15 & 0 & 2.62 & & 15 & 0 & 5.52 & \\
\hline 15 & 10 & 2.08 & -20.6 & 15 & 10 & 5.01 & -9.2 \\
\hline 15 & 15 & 1.34 & -48.9 & 15 & 15 & 6.01 & 8.9 \\
\hline 60.3 & 0 & 4.54 & & 60.4 & 0 & 4.07 & \\
\hline 60.4 & 10 & 4.88 & 7.5 & 60.4 & 10 & 3.66 & -10.1 \\
\hline 60.4 & 15 & 4.41 & -2.9 & 60.4 & 15 & 4.39 & 7.9 \\
\hline 105.6 & 0 & 3.93 & & 105.6 & 0 & 4.42 & \\
\hline 105.6 & 10 & 4.85 & 23.4 & 105.6 & 10 & 4.14 & -6.3 \\
\hline 105.6 & 15 & 4.69 & 19.3 & 105.6 & 15 & 4.76 & 7.7 \\
\hline 165.7 & 0 & 6.72 & & 165.9 & 0 & 7.23 & \\
\hline 165.9 & 10 & 8.11 & 20.7 & 165.9 & 10 & 6.36 & -12.0 \\
\hline 165.9 & 15 & 8.46 & 25.9 & 165.9 & 15 & 2.76 & -61.8 \\
\hline 224.1 & 0 & 6.35 & & 218.1 & 0 & 6.26 & \\
\hline 206.2 & 10 & 7.13 & 12.3 & 201.6 & 10 & 6.25 & -0.2 \\
\hline 202.8 & 15 & 7.45 & 17.3 & 196.9 & 15 & 2.49. & -60.2 \\
\hline $2,500 \mathrm{rpm}$ & & & & $1,320 \mathrm{rpm}$ & & & \\
\hline 14.9 & 0 & 1.08 & & 15 & 0 & 4.62 & \\
\hline 15 & 10 & 1.33 & 23.1 & 15 & 10 & 6.98 & 51.1 \\
\hline 15 & 15 & 1.5 & 38.9 & 15 & 15 & 5.77 & 24.9 \\
\hline 60.4 & 0 & 3.47 & & 60.4 & 0 & 4.4 & \\
\hline 60.4 & 10 & 4.33 & 24.8 & 60.4 & 10 & 4.88 & 10.9 \\
\hline 60.4 & 15 & 4.33 & 24.8 & 60.4 & 15 & 5.25 & 19.3 \\
\hline 105.6 & 0 & 4.41 & & 105.6 & 0 & 6.03 & \\
\hline 105.6 & 10 & 4.82 & 9.3 & 105.6 & 10 & 6.94 & 15.1 \\
\hline 105.6 & 15 & 4.53 & 2.7 & 105.6 & 15 & 7.17 & 18.9 \\
\hline 165.9 & 0 & 4.64 & & 201.8 & 0 & 4.63 & \\
\hline 165.9 & 10 & 6.88 & 48.3 & 189.5 & 10 & 2.19 & -52.7 \\
\hline 165.9 & 15 & 7.18 & 54.7 & 177.5 & 15 & 0.73 & -84.2 \\
\hline 236 & 0 & 6.06 & & & & & \\
\hline 216.7 & 10 & 7.15 & 18.0 & & & & \\
\hline 216 & 15 & 7.28 & 20.1 & & & & \\
\hline \multicolumn{8}{|l|}{$2,000 \mathrm{rpm}$} \\
\hline 15 & 0 & 2.78 & & & & & \\
\hline 15 & 10 & 3.1 & 11.5 & & & & \\
\hline 15 & 15 & 2.47 & -11.2 & & & & \\
\hline 60.4 & 0 & 3.39 & & & & & \\
\hline 60.4 & 10 & 4.09 & 20.6 & & & & \\
\hline 60.4 & 15 & 4.19 & 23.6 & & & & \\
\hline 105.6 & 0 & 3.11 & & & & & \\
\hline 105.6 & 10 & 3.85 & 23.8 & & & & \\
\hline 105.6 & 15 & 4.09 & 31.5 & & & & \\
\hline 166 & 0 & 4.1 & & & & & \\
\hline 165.9 & 10 & 4.22 & 2.9 & & & & \\
\hline 165.9 & 15 & 7.25 & 76.8 & & & & \\
\hline 239.9 & 0 & 5.83 & & & & & \\
\hline 220.6 & 10 & 6.88 & 18.0 & & & & \\
\hline 220.5 & 15 & 7.27 & 24.7 & & & & \\
\hline
\end{tabular}


Table A.4 Unburned Hydrocarbon Emissions Data

\begin{tabular}{|c|c|c|c|c|c|c|c|}
\hline $\begin{array}{c}\text { Torque } \\
\text { (Nm) }\end{array}$ & $\begin{array}{c}\text { Ethanol } \\
(\%)\end{array}$ & $\begin{array}{c}\text { BSHC } \\
\text { (g/kWh) }\end{array}$ & $\begin{array}{c}\text { Change } \\
(\%)\end{array}$ & $\begin{array}{c}\text { Torque } \\
\text { (Nm) }\end{array}$ & $\begin{array}{c}\text { Ethanol } \\
(\%)\end{array}$ & $\begin{array}{c}\text { BSHC } \\
\text { (g/kWh) }\end{array}$ & $\begin{array}{c}\text { Change } \\
(\%)\end{array}$ \\
\hline $3,000 \mathrm{rpm}$ & & & & $1,500 \mathrm{rpm}$ & & & \\
\hline 15 & 0 & 26.04 & & 15 & 0 & 11.33 & \\
\hline 15 & 10 & 15.1 & -42.0 & 15 & 10 & 1.69 & -85.1 \\
\hline 15 & 15 & 84.92 & 226.1 & 15 & 15 & 1.68 & -85.2 \\
\hline 60.3 & 0 & 1.02 & & 60.4 & 0 & 2.5 & \\
\hline 60.4 & 10 & 0.9 & -11.8 & 60.4 & 10 & 0.43 & -82.8 \\
\hline 60.4 & 15 & 1.2 & 17.6 & 60.4 & 15 & 0.39 & -84.4 \\
\hline 105.6 & 0 & 0.27 & & 105.6 & 0 & 1.52 & \\
\hline 105.6 & 10 & 0.44 & 63.0 & 105.6 & 10 & 0.53 & -65.1 \\
\hline 105.6 & 15 & 0.4 & 48.1 & 105.6 & 15 & 0.52 & -65.8 \\
\hline 165.7 & 0 & 0.14 & & 165.9 & 0 & 0.94 & \\
\hline 165.9 & 10 & 0.3 & 114.3 & 165.9 & 10 & 0.39 & -58.5 \\
\hline 165.9 & 15 & 0.27 & 92.9 & 165.9 & 15 & 0.43 & -54.3 \\
\hline 224.1 & 0 & 0.15 & & 218.1 & 0 & 3.05 & \\
\hline 206.2 & 10 & 0.38 & 153.3 & 201.6 & 10 & 0.39 & -87.2 \\
\hline 202.8 & 15 & 0.33 & 120.0 & 196.9 & 15 & 0.46 & -84.9 \\
\hline $2,500 \mathrm{rpm}$ & & & & $1,320 \mathrm{rpm}$ & & & \\
\hline 14.9 & 0 & 53.31 & & 15 & 0 & 2.49 & \\
\hline 15 & 10 & 36.14 & -32.2 & 15 & 10 & 2.21 & -11.2 \\
\hline 15 & 15 & 42.89 & -19.5 & 15 & 15 & 2.3 & -7.6 \\
\hline 60.4 & 0 & 0.61 & & 60.4 & 0 & 0.65 & \\
\hline 60.4 & 10 & 0.91 & 49.2 & 60.4 & 10 & 1 & 53.8 \\
\hline 60.4 & 15 & 0.87 & 42.6 & 60.4 & 15 & 1.28 & 96.9 \\
\hline 105.6 & 0 & 0.21 & & 105.6 & 0 & 0.3 & \\
\hline 105.6 & 10 & 0.47 & 123.8 & 105.6 & 10 & 0.57 & 90.0 \\
\hline 105.6 & 15 & 0.39 & 85.7 & 105.6 & 15 & 0.56 & 86.7 \\
\hline 165.9 & 0 & 0.21 & & 201.8 & 0 & 0.16 & \\
\hline 165.9 & 10 & 0.34 & 61.9 & 189.5 & 10 & 0.41 & 156.3 \\
\hline 165.9 & 15 & 0.35 & 66.7 & 177.5 & 15 & 0.42 & 162.5 \\
\hline 236 & 0 & 0.15 & & & & & \\
\hline 216.7 & 10 & 0.41 & 173.3 & & & & \\
\hline 216 & 15 & 0.42 & 180.0 & & & & \\
\hline \multicolumn{8}{|l|}{$2,000 \mathrm{rpm}$} \\
\hline 15 & 0 & 16.54 & & & & & \\
\hline 15 & 10 & 3.69 & -77.7 & & & & \\
\hline 15 & 15 & 5.19 & -68.6 & & & & \\
\hline 60.4 & 0 & 0.42 & & & & & \\
\hline 60.4 & 10 & 0.83 & 97.6 & & & & \\
\hline 60.4 & 15 & 0.93 & 121.4 & & & & \\
\hline 105.6 & 0 & 0.31 & & & & & \\
\hline 105.6 & 10 & 0.45 & 45.2 & & & & \\
\hline 105.6 & 15 & 0.53 & 71.0 & & & & \\
\hline 166 & 0 & 0.19 & & & & & \\
\hline 165.9 & 10 & 0.66 & 247.4 & & & & \\
\hline 165.9 & 15 & 0.13 & -31.6 & & & & \\
\hline 239.9 & 0 & 0.15 & & & & & \\
\hline 220.6 & 10 & 0.39 & 160.0 & & & & \\
\hline 220.5 & 15 & 0.46 & 206.7 & & & & \\
\hline
\end{tabular}


Table A.5 Carbon Monoxide Emissions Data

\begin{tabular}{|c|c|c|c|c|c|c|c|}
\hline $\begin{array}{c}\text { Torque } \\
\text { (Nm) }\end{array}$ & $\begin{array}{c}\text { Ethanol } \\
(\%)\end{array}$ & $\begin{array}{c}\text { BSCO } \\
\text { (g/kWh) }\end{array}$ & $\begin{array}{c}\text { Change } \\
(\%)\end{array}$ & $\begin{array}{c}\text { Torque } \\
\text { (Nm) }\end{array}$ & $\begin{array}{c}\text { Ethanol } \\
(\%)\end{array}$ & $\begin{array}{c}\text { BSCO } \\
\text { (g/kWh) }\end{array}$ & $\begin{array}{c}\text { Change } \\
(\%)\end{array}$ \\
\hline $3,000 \mathrm{rpm}$ & & & & $1,500 \mathrm{rpm}$ & & & \\
\hline 15 & 0 & 64.89 & & 15 & 0 & 11.33 & \\
\hline 15 & 10 & 41.93 & -35.4 & 15 & 10 & 10.99 & -3.0 \\
\hline 15 & 15 & 109.4 & 68.6 & 15 & 15 & 14.03 & 23.8 \\
\hline 60.3 & 0 & 6.16 & & 60.4 & 0 & 2.5 & \\
\hline 60.4 & 10 & 4.01 & -34.9 & 60.4 & 10 & 2.69 & 7.6 \\
\hline 60.4 & 15 & 5.68 & -7.8 & 60.4 & 15 & 3.15 & 26.0 \\
\hline 105.6 & 0 & 1.1 & & 105.6 & 0 & 1.52 & \\
\hline 105.6 & 10 & 0.96 & -12.7 & 105.6 & 10 & 1.4 & -7.9 \\
\hline 105.6 & 15 & 1.04 & -5.5 & 105.6 & 15 & 1.1 & -27.6 \\
\hline 165.7 & 0 & 0.43 & & 165.9 & 0 & 0.94 & \\
\hline 165.9 & 10 & 0.4 & -7.0 & 165.9 & 10 & 0.41 & -56.4 \\
\hline 165.9 & 15 & 0.47 & 9.3 & 165.9 & 15 & 0.34 & -63.8 \\
\hline 224.1 & 0 & 0.74 & & 218.1 & 0 & 3.05 & \\
\hline 206.2 & 10 & 0.58 & -21.6 & 201.6 & 10 & 0.72 & -76.4 \\
\hline 202.8 & 15 & 0.57 & -23.0 & 196.9 & 15 & 0.53 & -82.6 \\
\hline $2,500 \mathrm{rpm}$ & & & & $1,320 \mathrm{rpm}$ & & & \\
\hline 14.9 & 0 & 102.08 & & 15 & 0 & 16.1 & \\
\hline 15 & 10 & 73.58 & -27.9 & 15 & 10 & 14.13 & -12.2 \\
\hline 15 & 15 & 80.41 & -21.2 & 15 & 15 & 17.04 & 5.8 \\
\hline 60.4 & 0 & 3.17 & & 60.4 & 0 & 1.97 & \\
\hline 60.4 & 10 & 2.25 & -29.0 & 60.4 & 10 & 2.37 & 20.3 \\
\hline 60.4 & 15 & 2.58 & -18.6 & 60.4 & 15 & 2.73 & 38.6 \\
\hline 105.6 & 0 & 0.84 & & 105.6 & 0 & 1.26 & \\
\hline 105.6 & 10 & 0.84 & 0.0 & 105.6 & 10 & 1.01 & -19.8 \\
\hline 105.6 & 15 & 0.91 & 8.3 & 105.6 & 15 & 0.86 & -31.7 \\
\hline 165.9 & 0 & 0.49 & & 201.8 & 0 & 15.69 & \\
\hline 165.9 & 10 & 0.41 & -16.3 & 189.5 & 10 & 5.55 & -64.6 \\
\hline 165.9 & 15 & 0.41 & -16.3 & 177.5 & 15 & 3.49 & -77.8 \\
\hline 236 & 0 & 0.78 & & & & & \\
\hline 216.7 & 10 & 0.58 & -25.6 & & & & \\
\hline 216 & 15 & 0.53 & -32.1 & & & & \\
\hline \multicolumn{8}{|l|}{$2,000 \mathrm{rpm}$} \\
\hline 15 & 0 & 44.67 & & & & & \\
\hline 15 & 10 & 33.47 & -25.1 & & & & \\
\hline 15 & 15 & 45.27 & 1.3 & & & & \\
\hline 60.4 & 0 & 1.92 & & & & & \\
\hline 60.4 & 10 & 1.82 & -5.2 & & & & \\
\hline 60.4 & 15 & 2.16 & 12.5 & & & & \\
\hline 105.6 & 0 & 1.08 & & & & & \\
\hline 105.6 & 10 & 1.01 & -6.5 & & & & \\
\hline 105.6 & 15 & 1.09 & 0.9 & & & & \\
\hline 166 & 0 & 0.48 & & & & & \\
\hline 165.9 & 10 & 0.38 & -20.8 & & & & \\
\hline 165.9 & 15 & 0.39 & -18.8 & & & & \\
\hline 239.9 & 0 & 0.7 & & & & & \\
\hline 220.6 & 10 & 0.51 & -27.1 & & & & \\
\hline 220.5 & 15 & 0.41 & -41.4 & & & & \\
\hline
\end{tabular}


Table A.6 Idling Data

\begin{tabular}{|lccc|}
\hline & \multicolumn{3}{c|}{ Emissions $(\mathbf{g} / \mathbf{h})$ per Ethanol Content } \\
\cline { 2 - 4 } Pollutant $^{\mathrm{a}}$ & $\mathbf{0 \%}$ & $\mathbf{1 0 \%}$ & $\mathbf{1 5 \%}$ \\
\hline & & & \\
$\mathrm{NO}_{\mathrm{x}}$ & 17.4994016 & 15.9582802 & 16.5855716 \\
$\mathrm{PM}_{10}$ & 39.2210494 & 62.2236391 & 38.2799107 \\
$\mathrm{THC}$ & 5.44266301 & 7.16755495 & 5.64879137 \\
$\mathrm{CO}$ & 32.781154 & 34.1912419 & 39.1139927 \\
\hline
\end{tabular}

a $\mathrm{NO}_{\mathrm{x}}=$ nitrogen oxides; $\mathrm{PM}_{10}=$ particulate matter with a mean aerodynamic diameter of $10 \mu \mathrm{m}$ or less; THC $=$ total hydrocarbons; $\mathrm{CO}=$ carbon monoxide. 